\title{
A New Safety Factor Prediction Model for Mass Concrete Surface Cracking in Early Age
}

\author{
Sheng Qiang ${ }^{1,2}$ and Min-zhi Liu ${ }^{1,3}$ \\ ${ }^{1}$ College of Water Conservancy and Hydropower Engineering, Hohai University, Nanjing 210098, China \\ ${ }^{2}$ School of Civil Engineering, Purdue University, 550 Stadium Mall Drive, West Lafayette, IN 47907, USA \\ ${ }^{3}$ Zhoushan Financial Project Budget Audit Center, Zhoushan Finance Bureau, Zhoushan 316021, China
}

Correspondence should be addressed to Sheng Qiang; sqiang2118@hhu.edu.cn

Received 6 December 2013; Accepted 4 February 2014; Published 18 March 2014

Academic Editor: Fei Kang

Copyright (C) 2014 S. Qiang and M.-z. Liu. This is an open access article distributed under the Creative Commons Attribution License, which permits unrestricted use, distribution, and reproduction in any medium, provided the original work is properly cited.

\begin{abstract}
The temperature difference between mass concrete inside and outside is an important index to prevent the structure surface cracking, but the definition and the application criterion are not very clear till now. In this paper, the surface concrete temperature spatial gradient in $0.5 \mathrm{~m}$ deep is found as a more reasonable and feasible index. Then a new model, which can be used to calculate the surface safety factor simply, is deduced in three steps. First, a basic model is created under the simplest boundary condition. Then the feasibility of the basic model is analyzed under different boundary conditions and the model is improved. At last, according to the comparison of different concrete materials, the improved model is calibrated further. With the help of the proposed model, the surface safety factor can be adjusted by observing and controlling the temperature spatial gradient dynamically, which will bring convenience to designer and constructor.
\end{abstract}

\section{Introduction}

One of the hard tasks of concrete structure in research and application is cracking prevention or mitigation. In the running period, concrete structure tends to become damaged and cracked because of some extreme conditions, such as fire or freeze-thaw, which may cause obvious strength reduction $[1,2]$. On the other hand, many cracks usually tend to form in the early age of concrete [3,4], even under well-designed construction conditions. The early age cracking reasons include many factors, such as humidity gradient, autogenous shrinkage, temperature gradient, structure restraint, and casting block shape and size. According to the observation on some concrete dams, the surface cracks of mass concrete caused by humidity gradient are not severe as thin concrete structure. The material researchers have created many methods to reduce the drying and autogenous shrinkage $[5,6]$. The structure and construction researchers of mass concrete put more emphasis on the later three factors, especially the temperature gradient $[7,8]$. Some effective temperature control methods have been implemented in mass concrete structure, such as pipe cooling, surface covering, and low casting temperature. Pipe cooling can decrease the inside temperature of mass concrete. Some researchers proposed pipe simulation models to predict the inside temperature and stress, which increase the reliability of inner cracking prevention of mass concrete [9-11].

The surface cracking of concrete in early age is related to the temperature difference between inside and outside. In fact, as the index of the temperature control and crack prevention, the control of the temperature difference between inside and outside is the control of the influence of concrete temperature spatial gradient on concrete thermal stress. As for some mass concrete, especially the concrete dam pouring blocks which are not in the base restraint area, the inside temperature in early age may be high, but the inside stress may not be so high because its temperature spatial gradient is not large. For the surface concrete, the large temperature spatial gradient always leads to large tensile stress which will cause fracture [12-15]. The reason is the inharmonious deformation in different areas. 


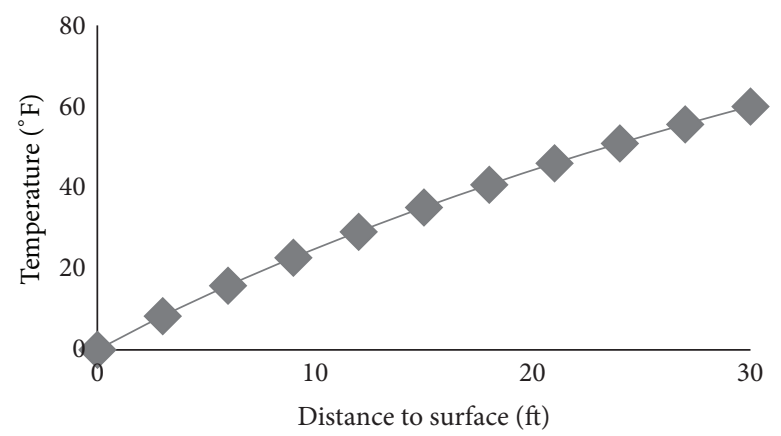

FIgURE 1: Assumed relation of temperature and distance to surface.

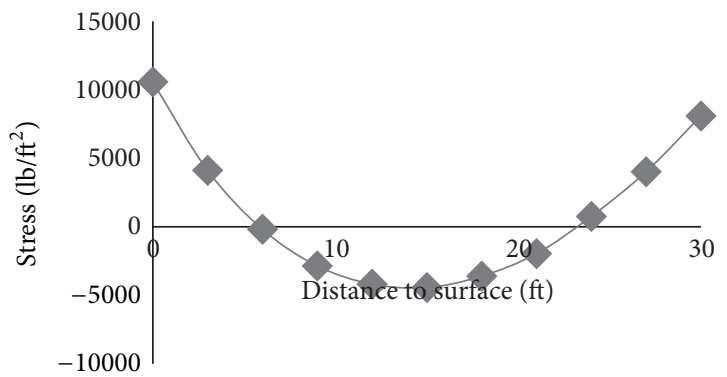

FIGURE 2: Calculated relation of stress and distance to surface.

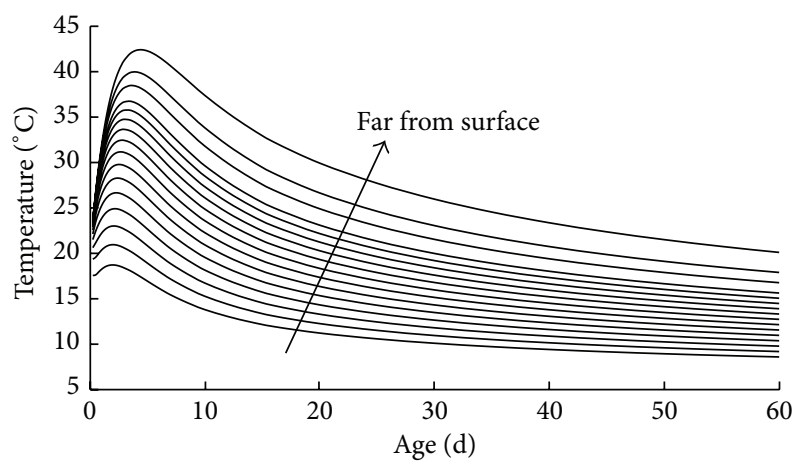

FIGURE 3: The temperature development curves of the survey points with different distances from surface in 60.0 days.

Although the temperature difference between inside and outside is an important index, the definition and the application criterion are not very clear till now, even in the design standard or construction standard. According to the experience of author, the definition and the criterion are correlative. Because of the unclear definition, the different criteria suggested by different researchers for a same object always cause puzzle in engineering application. This paper tries to deduce a new model which is simple to solve such problem.

In the published literatures, it is difficult to find a convenient and scientific prediction model for surface cracking control of mass concrete. A common used model in US Bureau of Reclamation to calculate the stress caused by temperature gradient is recommended [16]. The model can predict the stress caused by the temperature gradient in a certain thickness. An example with some data was shown in a table of this book. In this sample, some basic data and an assumed temperature distribution along concrete thickness was shown in a table; then the stresses were computed in the table with the recommended model. We plot the temperature and stress of the sample in Figures 1 and 2. Figure 1 shows the relationship of temperature and distance to surface, and Figure 2 shows the relationship of stress and distance to surface. It can be found that the stress distribution near surface changes from tensile stress to pressure stress with the temperature increasing, which is similar to the finite element solution. However, the stress inside concrete becomes from pressure stress to tensile stress with the temperature keeping increasing, which is sharply different with finite element solution. The common solution of nowadays is that, in the early age, when the surface temperature is lower than inside, tensile stress will occur near surface and pressure stress will occur inside, while in the later age, when the surface temperature is higher than inside, pressure stress will occur near surface and tensile stress will occur inside. On the other hand, the assumed temperature gradient in this example can only describe the mature age. Actually, in the early age, the temperature gradient near surface will be much greater than inside and it should be nonlinear as well.

In order to control the tensile stress developing in early age on concrete surface, a cracking safety factor $K$ can be defined as the ratio of tensile strength to tensile stress. This definition means when the $K$ is lower than 1.0, the obvious crack can be found by human eye.

As for the common situation, the main influence factors of the surface cracking safety for mass concrete in early age include concrete elastic module, tension strength, and temperature spatial gradient in surface layer.

The relation between temperature spatial gradient and surface cracking safety in different situations is researched in this paper. The results show that the safety factor will decrease when the concrete elastic module and the temperature spatial gradient increase, while it will increase when the concrete tension strength increases. The last proposed model is feasible to control the surface safety by observing and controlling the temperature spatial gradient, which will make it easier for the designer or constructor to get the reasonable index of temperature spatial gradient. 


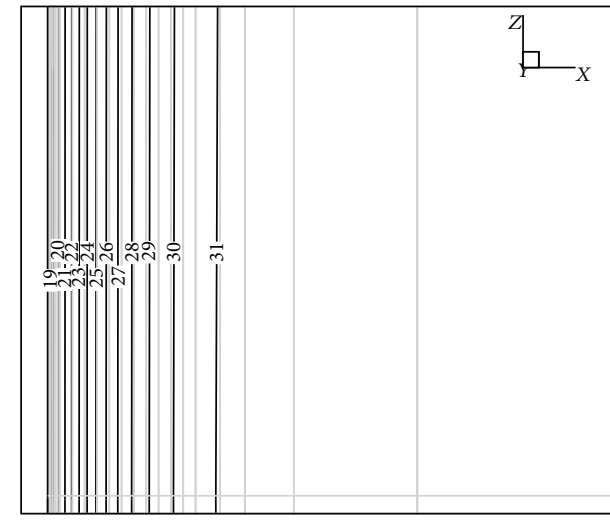

Age $1.0 \mathrm{~d}$

(a)

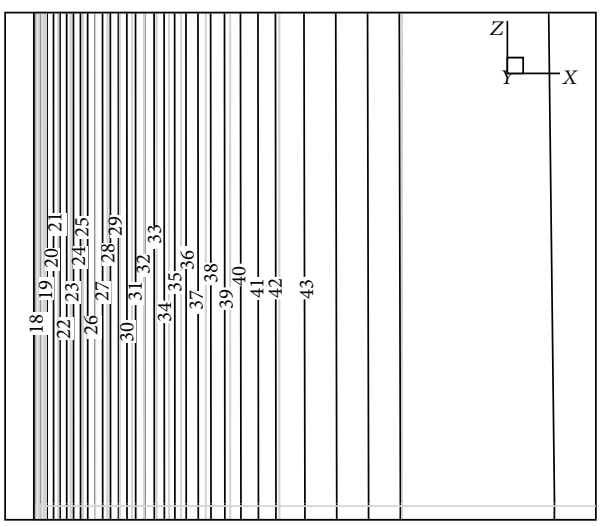

Age $5.0 \mathrm{~d}$

(c)

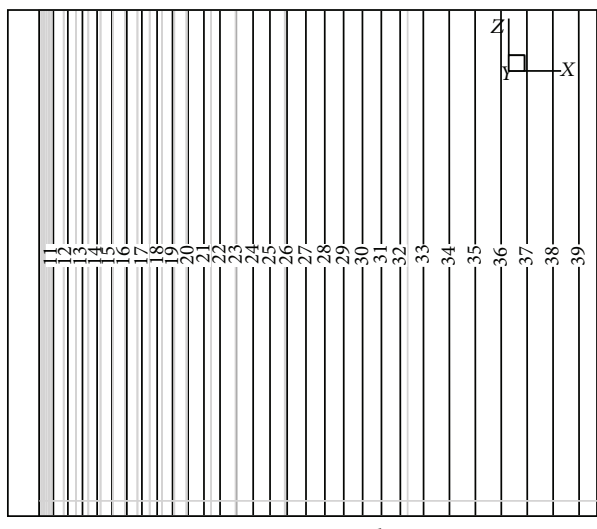

Age $30.0 \mathrm{~d}$

(e)

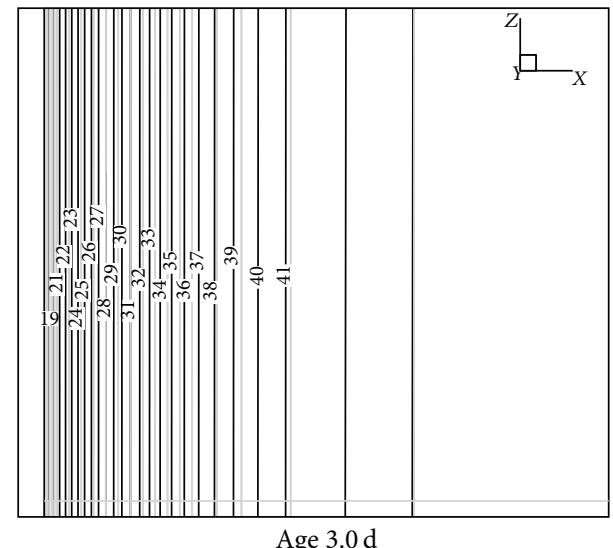

(b)

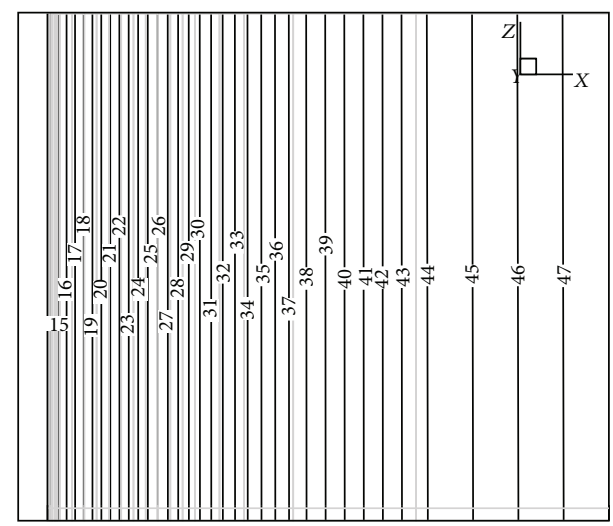

Age $10.0 \mathrm{~d}$

(d)

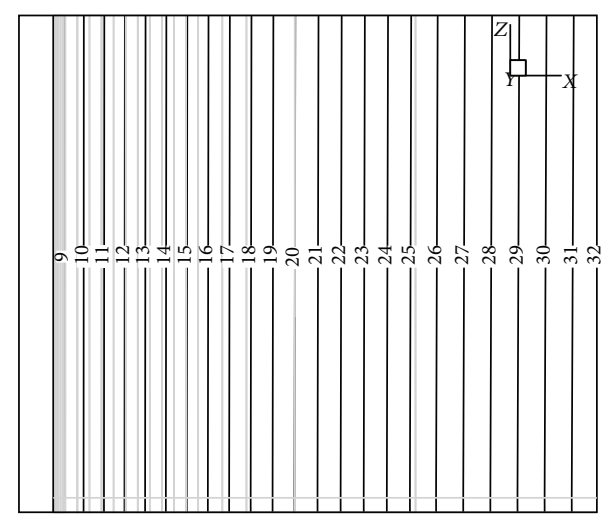

Age $60.0 \mathrm{~d}$

(f)

FIGURE 4: Temperature contours in $1.0 \mathrm{~m}$ deep area at different ages $\left({ }^{\circ} \mathrm{C}\right)$.

TABLE 1: Main concrete material parameters in basic model deduction.

\begin{tabular}{|c|c|c|c|c|c|c|c|c|c|}
\hline \multirow{2}{*}{ Material parameters } & \multicolumn{3}{|c|}{$\begin{array}{c}\text { Adiabatic temperature rising }\left({ }^{\circ} \mathrm{C}\right) \\
\theta(\tau)=T_{0} \times\left(1-e^{-a \tau^{b}}\right)\end{array}$} & \multicolumn{3}{|c|}{$\begin{array}{l}\text { Elastic module }(\mathrm{GPa}) \\
E(\tau)=E_{0} \times\left(1-e^{-a \tau^{b}}\right)\end{array}$} & \multicolumn{3}{|c|}{$\begin{array}{l}\text { Tensile strength }(\mathrm{MPa}) \\
f_{t}(\tau)=f_{0} \times\left(1-e^{-a \tau^{b}}\right)\end{array}$} \\
\hline & $\theta_{0}$ & $a$ & $b$ & $E_{0}$ & $a$ & $b$ & $f_{t}$ & $a$ & $b$ \\
\hline & 20.0 & 0.50 & 1.00 & 35.0 & 0.75 & 0.50 & 3.25 & 0.75 & 0.50 \\
\hline
\end{tabular}




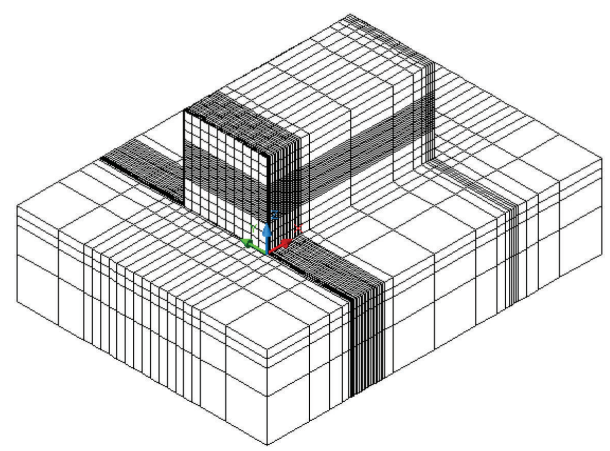

Figure 5: The finite element test model.

TABLE 2: The detailed condition of case series 1.

\begin{tabular}{|c|c|c|c|}
\hline Case & $\begin{array}{c}\text { Air } \\
\text { temperature } \\
T_{a}\left({ }^{\circ} \mathrm{C}\right)\end{array}$ & $\begin{array}{c}\text { Pouring } \\
\text { temperature } \\
T_{0}\left({ }^{\circ} \mathrm{C}\right)\end{array}$ & Note \\
\hline $1-1$ & 30.0 & \multirow{6}{*}{20.0} & \multirow{6}{*}{$\begin{array}{l}\text { No pipe cooling, no } \\
\text { surface insulation, no } \\
\text { daily variation of air } \\
\text { temperature }\end{array}$} \\
\hline $1-2$ & 25.0 & & \\
\hline $1-3$ & 20.0 & & \\
\hline $1-4$ & 15.0 & & \\
\hline $1-5$ & 10.0 & & \\
\hline $1-6$ & 5.0 & & \\
\hline
\end{tabular}

The deduction of the new model can be separated into three steps which will be shown in the following paragraphs. At first, the basic model is created under the simplest boundary condition. Then the feasibility of the basic model is analyzed under different boundary conditions and the model is improved. At last, according to the comparison of different concrete materials, the improved model is calibrated further and then the practical formula of the concrete surface safety factor model is proposed.

\section{Deduction of Basic Model}

2.1. The Research Object. After the calculation of a concrete pouring block in 60.0 days with finite element method (FEM), the temperature field in the $1.0 \mathrm{~m}$ deep area near surface is gotten. Figure 3 shows the temperature development curves of the survey points with different distances from surface during 60.0 days. The distance of the 16 points to surface varies from $0.00 \mathrm{~m}$ to $1.00 \mathrm{~m}$ with an increment of $0.05 \mathrm{~m}$. It can be seen form Figure 3 that the deeper points have higher temperature and lower temperature spatial gradient. Figure 4 shows the temperature contours near surface in different ages. It can be seen when the age is over $10.0 \mathrm{~d}$ the temperature spatial gradient in the surface of $1.0 \mathrm{~m}$ deep area is nearly same; else the temperature field in the area of only $0.5 \mathrm{~m}$ deep changes evenly. Therefore, the research object of this paper will be selected as the area of $0.5 \mathrm{~m}$ deep.

2.2. The Finite Element Test Model and Calculation Case Series 1. The finite element test model is a large-scale concrete block with the dimension of $40 \mathrm{~m} \times 20 \mathrm{~m} \times 20 \mathrm{~m}$ on a base, which is shown in Figure 5. In order to improve the calculation precision, the surface concrete mesh is refined.

The main material parameters of the concrete can be found in Table 1. During the deduction course of the basic formula, some factors are not considered to simplify the boundary conditions, including the daily variation of air temperature, pipe cooling, and surface insulation measures. The influence of these factors will be analyzed further in the later paragraphs.

Table 2 shows 6 cases of series 1 with the same initial temperature $20^{\circ} \mathrm{C}$, in which the air temperature is changed to form the different temperature spatial gradient in the surface concrete.

The three-dimensional finite element method for unsteady temperature field and stress field [9] are applied in the construction simulation for the test block.

2.3. Deduction of the Basic Formula. On the basis of calculation result of case series 1 , the relation between the surface safety factor $K$ and concrete temperature spatial gradient $\partial T / \partial l$ at different ages is described in Figure 6. The safety factor $K$ equals $\sigma_{t} / \sigma_{1}$, where $\sigma_{1}$ is the first principle stress of surface point and $\sigma_{t}$ is the tensile strength at the same age. $\partial T / \partial l$ is the average temperature spatial gradient in the $0.5 \mathrm{~m}$ deep area, which can be measured easily by the temperature sensors in concrete. The following conclusion can be gotten according to Figure 6.

(1) With the growing of concrete age, the temperature spatial gradient increases first and then decreases. The concrete inside temperature keeps rising after concrete pouring because of hydration reaction, while the air temperature is assumed to be steady. So the temperature spatial gradient keeps rising. When the inside temperature arrives at the peak, it begins to drop. So temperature spatial gradient begins to decrease, too.

(2) With the growing of concrete age, the concrete surface safety factor decreased first and then increases a little. At the beginning of the age, the concrete elastic module and the stress are very small, so the surface safety factor is of large value. The growth of both the elastic module and the temperature spatial gradient induces the thermal stress increase rapidly, while the tensile strength increases relatively slowly. So the safety factor goes down fast. With the developing of concrete strength and the dropping of temperature spatial gradient, the safety factor grows gently in the later age.

(3) In every case, the relation curves between the temperature spatial gradient and the safety factor have the regular rule. The curves' shape is very similar and shows significant grading rule with the change of the air temperature.

Table 3 shows the safety factor and temperature spatial gradient at age $10 \mathrm{~d}$ in every case. The data in Table 3 can be fitted by a curve which can be described by different functions 

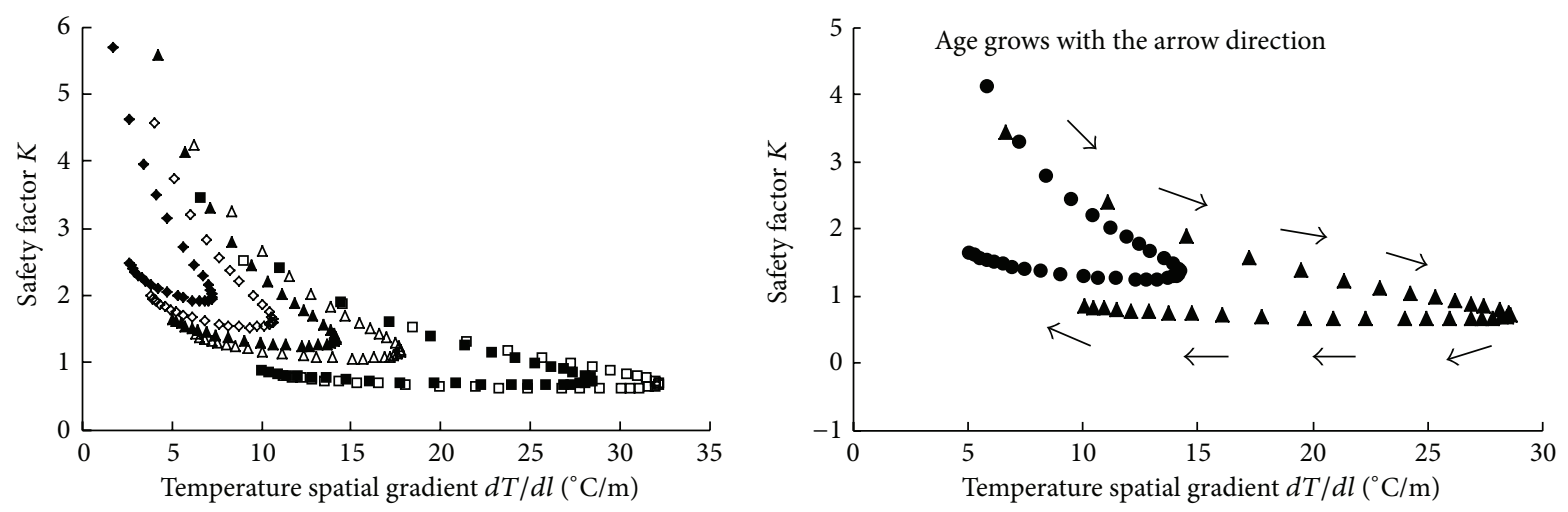

$\begin{array}{ll}- \text { Case } 1-1 & \diamond \text { Case } 1-2 \\ \Delta \text { Case } 1-3 & \Delta \text { Case } 1-4 \\ \text { Case } 1-5 & \square \text { Case } 1-6\end{array}$

(a)

(b)

FIGURE 6: Relation between safety factor and temperature spatial gradient in case series 1.

TABLE 3: Safety factor and temperature spatial gradient at age $10 \mathrm{~d}$ in case series 1.

\begin{tabular}{lcccccc}
\hline Case number & Case 1-1 & Case 1-2 & Case 1-3 & Case 1-4 & Case 1-5 & Case 1-6 \\
\hline$\partial T / \partial l\left({ }^{\circ} \mathrm{C} / \mathrm{m}\right)$ & 6.562 & 9.387 & 12.209 & 15.033 & 23.964 & 26.787 \\
$K$ & 1.906 & 1.526 & 1.258 & 1.070 & 0.656 & 0.601 \\
\hline
\end{tabular}

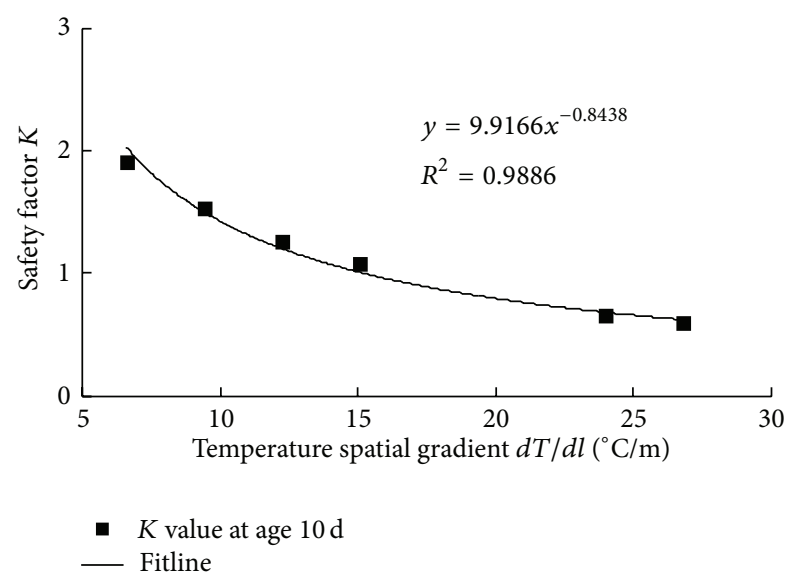

FigURE 7: Relation between safety factor and temperature spatial gradient at age $10 \mathrm{~d}$ in case series 1 .

well. To simplify the new model, the power function is adopted. The fit line can be seen in Figure 7.

From Figure 7 the temperature spatial gradient function $f(\partial T / \partial l)$ can be expressed by

$$
f\left(\frac{\partial T}{\partial l}\right)=9.9166 \times\left(\frac{\partial T}{\partial l}\right)^{-0.8438}
$$

Equation (1) is based on the relation curve of age $10 \mathrm{~d}$ only. Then the age factor will be introduced into the basic formula. If the relation curves as Figure 7 at every calculation step are drawn, the safety factor $K$ corresponding to the temperature spatial gradient of $10^{\circ} \mathrm{C} / \mathrm{m}$ can be interpolated.

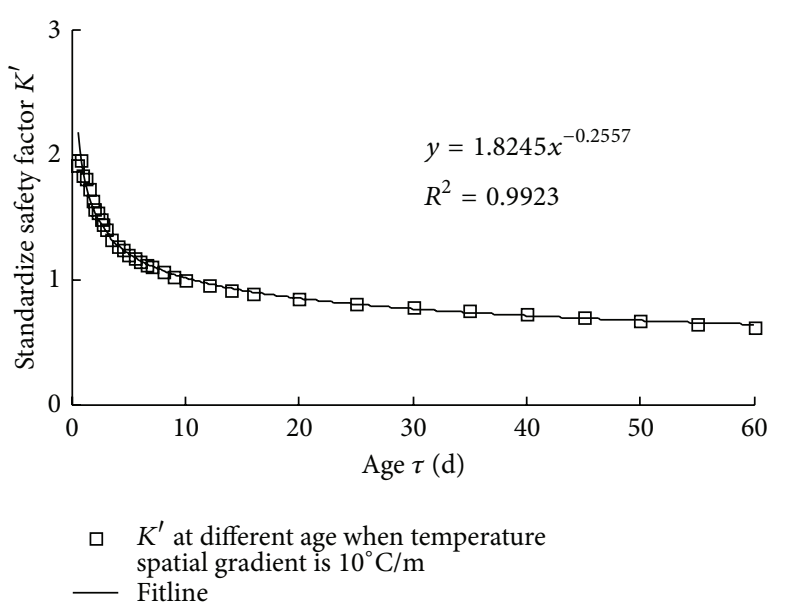

FIGURE 8: Relation between age and standardize safety factor $K^{\prime}$ when temperature spatial gradient is $10^{\circ} \mathrm{C} / \mathrm{m}$ in case series 1 .

Then these $K$ values can be divided by the $K$ value of age $10 \mathrm{~d}$; a standardized safety factor $K^{\prime}$ will be obtained. The values of the interpolated $K$ and the standardized $K^{\prime}$ at different ages are shown in Table 4. Based on Table 4, the relation between age and $K^{\prime}$ can be described by another power function, which is shown in Figure 8.

From Figure 8, the expression $g(\tau)$ to describe the age factor can be expressed by

$$
g(\tau)=1.8245 \times \tau^{-0.2557}
$$


TABLE 4: The interpolated $K$ and standardized $K^{\prime}$ at different ages.

\begin{tabular}{lccccccccccccc}
\hline Age (d) & 0.25 & 0.5 & 0.75 & 1 & 1.25 & 1.5 & 1.75 & 2 & 2.25 & 2.5 & 2.75 & 3 \\
\hline$K$ & & 2.80 & 2.87 & 2.68 & 2.65 & 2.52 & 2.39 & 2.30 & 2.25 & 2.18 & 2.11 & 2.05 \\
$K^{\prime}$ & & 1.91 & 1.96 & 1.83 & 1.81 & 1.72 & 1.63 & 1.57 & 1.53 & 1.49 & 1.44 & 1.40 \\
\hline Age (d) & 3.5 & 4 & 4.5 & 5 & 5.5 & 6 & 6.5 & 7 & 8 & 9 & 10 \\
\hline$K$ & 1.94 & 1.86 & 1.81 & 1.77 & 1.72 & 1.68 & 1.65 & 1.62 & 1.56 & 1.51 & 1.47 & 1.41 \\
$K^{\prime}$ & 1.32 & 1.27 & 1.24 & 1.20 & 1.17 & 1.15 & 1.12 & 1.10 & 1.06 & 1.03 & 1.00 & 0.96 \\
\hline Age (d) & 14 & 16 & 20 & 25 & 30 & 35 & 40 & 45 & 50 & 55 & 60 \\
\hline$K$ & 1.35 & 1.30 & 1.24 & 1.18 & 1.14 & 1.10 & 1.06 & 1.02 & 0.98 & 0.94 & 0.90 \\
$K^{\prime}$ & 0.92 & 0.88 & 0.85 & 0.80 & 0.78 & 0.75 & 0.72 & 0.70 & 0.67 & 0.64 & 0.62 \\
\hline
\end{tabular}

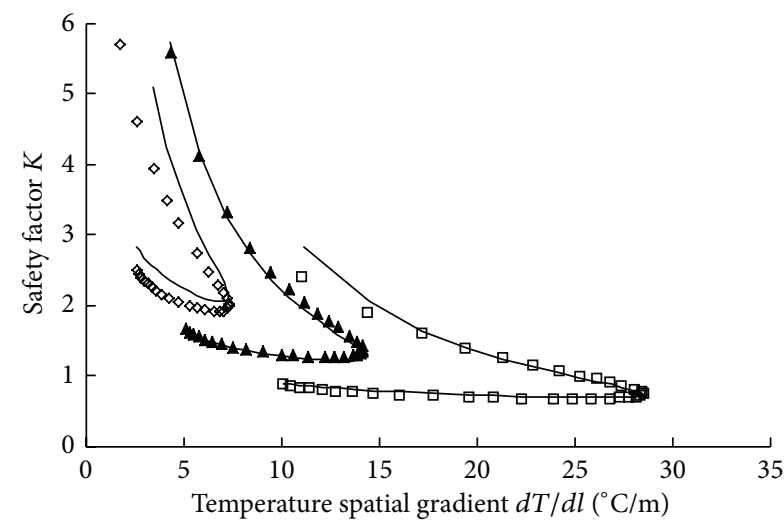

Case 1-1:

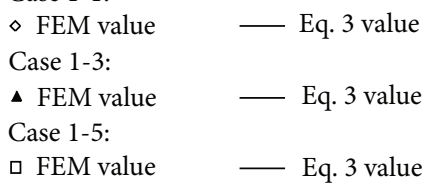

(a)

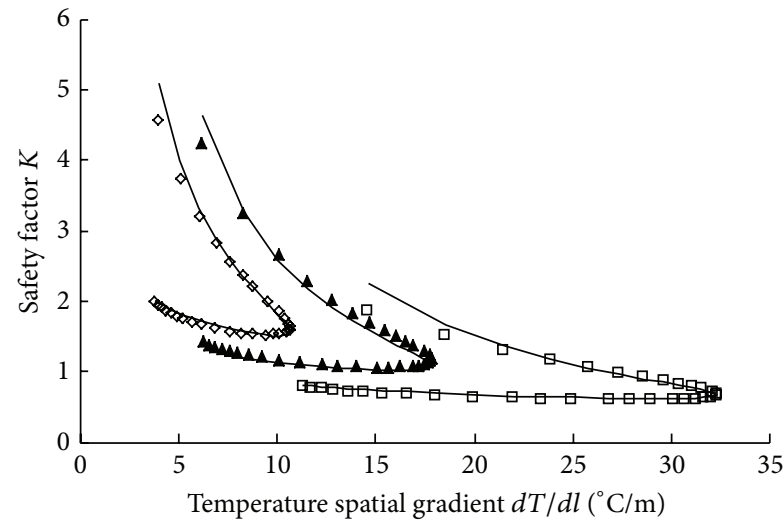

Case 1-2:
$\diamond$ FEM value
— Eq. 3 value
Case 1-4:
- FEM value
Case 1-6:
口 FEM value

(b)

Figure 9: The safety factor comparison between two methods. (a) Results of Cases 1-1, 1-3, and 1-5. (b) Results of Cases 1-2, 1-4, and 1-6.

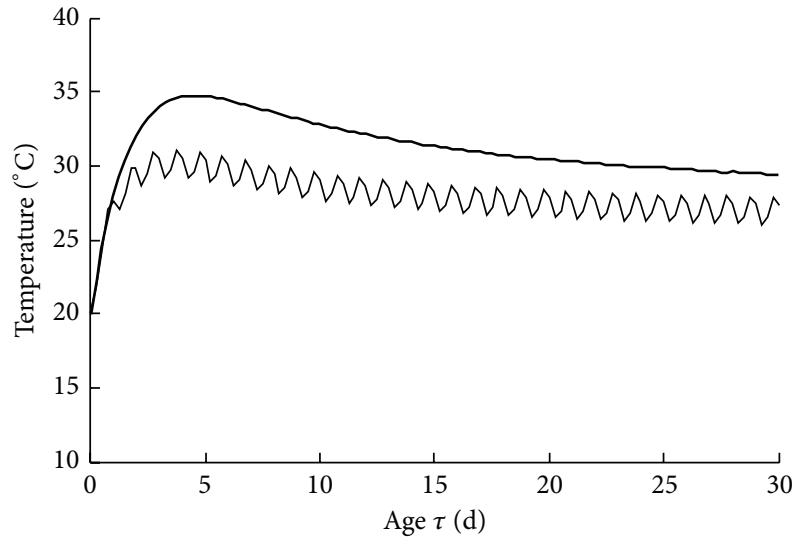

- Point of $0.5 \mathrm{~m}$ deep

_ Point of $0.05 \mathrm{~m}$ deep

FIGURE 10: Surface layer concrete temperature change with the daily variation of air temperature.

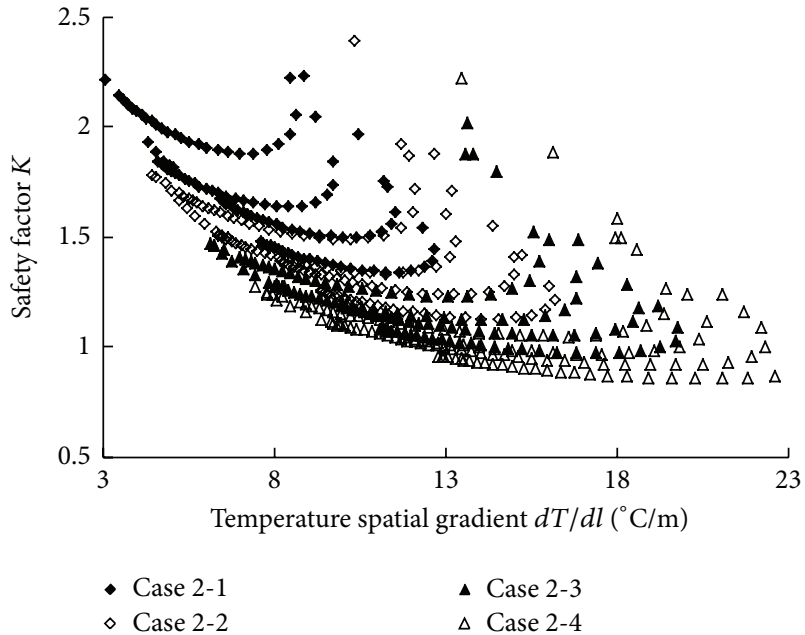

FIGURE 11: Relation between concrete surface safety factor and temperature spatial gradient in case series 2 . 
TABLE 5: Calculation condition in case series 2.

\begin{tabular}{lll}
\hline Case & $\begin{array}{c}\text { Air temperature } \\
T_{a}\left({ }^{\circ} \mathrm{C}\right)\end{array}$ & \multicolumn{1}{c}{ Note } \\
\hline $2-1$ & $25 \pm 5$ & The other condition is same \\
$2-2$ & $20 \pm 5$ & as case 1 \\
$2-3$ & $15 \pm 5$ & \\
$2-4$ & $10 \pm 5$ & \\
\hline
\end{tabular}

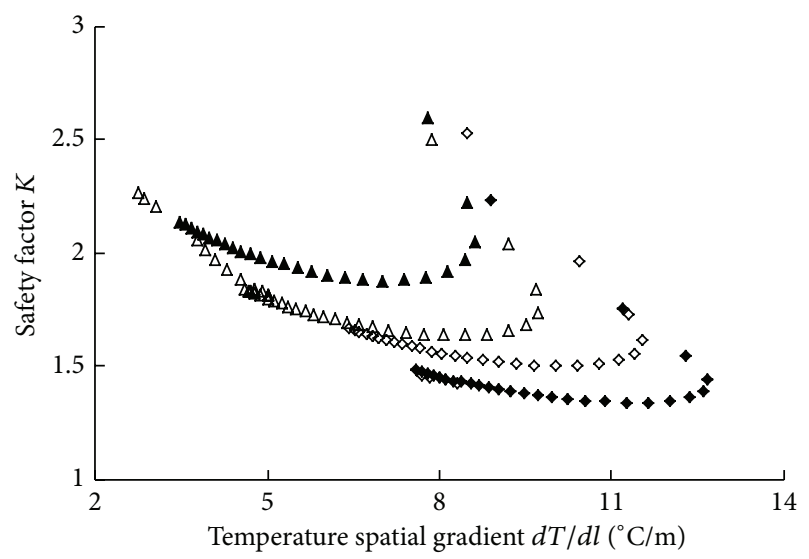

Case 2-1:
- $0.25 \mathrm{~d}$
$\Delta 0.75 \mathrm{~d}$
$\diamond 0.50 \mathrm{~d}$
$\Delta 0.00 \mathrm{~d}$

FIGURE 12: Relation between concrete surface safety factor and temperature spatial gradient at different times of every day in case $2-1$.

TABLE 6: Calculation condition in case series 3.

\begin{tabular}{lccl}
\hline Case & $\begin{array}{c}\text { Air } \\
\text { temperature } \\
T_{a}\left({ }^{\circ} \mathrm{C}\right)\end{array}$ & $\begin{array}{c}\text { Pipe inlet water } \\
\text { temperature } T_{w} \\
\left({ }^{\circ} \mathrm{C}\right)\end{array}$ & Note \\
\hline $3-1$ & 30.0 & & \\
$3-2$ & 25.0 & & The other condition is \\
$3-3$ & 20.0 & 15.0 & same as case 1 \\
$3-4$ & 15.0 & & \\
$3-5$ & 10.0 & & \\
$3-6$ & 5.0 & & \\
\hline
\end{tabular}

TABLE 7: Calculation condition of case series 4.

\begin{tabular}{lccl}
\hline Case & $\begin{array}{c}\text { Air } \\
\text { temperature } T_{a} \\
\left({ }^{\circ} \mathrm{C}\right)\end{array}$ & $\begin{array}{c}\text { Pipe inlet water } \\
\text { temperature } T_{w} \\
\left({ }^{\circ} \mathrm{C}\right)\end{array}$ & Note \\
\hline $4-1$ & $25.0 \pm 5.0$ & & $\begin{array}{l}\text { The other } \\
\text { calculation } \\
\text { condition is same as } \\
4-2\end{array}$ \\
$4-3$ & $20.0 \pm 5.0$ & 15.0 & \\
$4-4$ & $15.0 \pm 5.0$ & & case series 1. \\
\hline
\end{tabular}

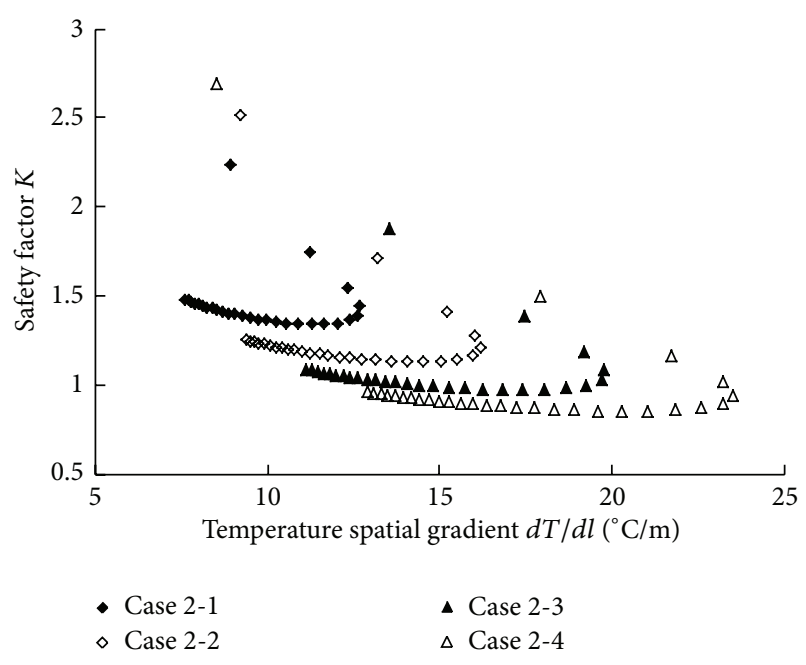

FIGURE 13: Relation between minimum surface safety factor and temperature spatial gradient in case series 2 .

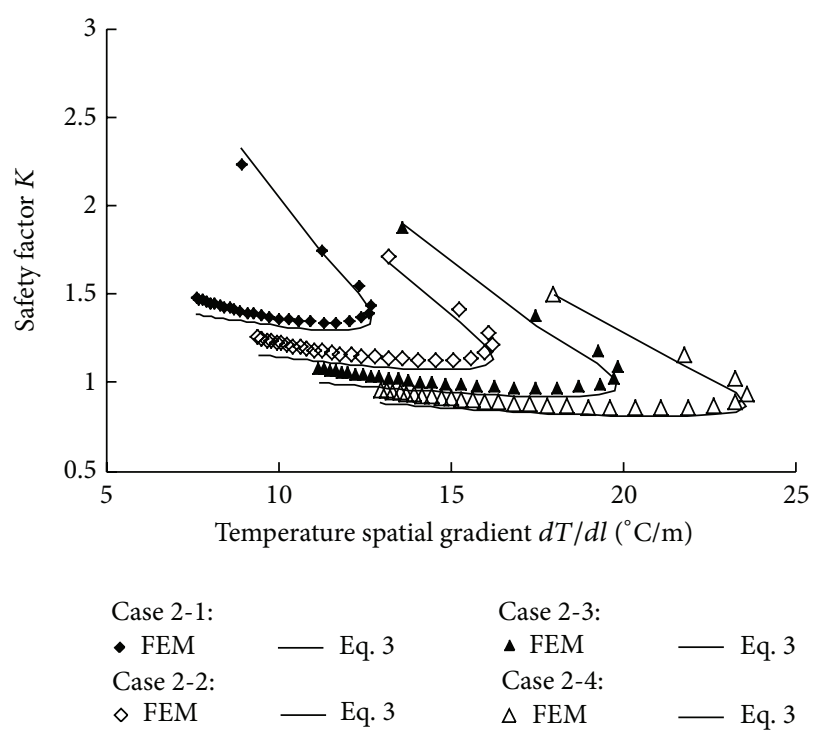

FIGURE 14: Comparison between calculated values by FEM and (3).

Multiplying (1) and (2), the basic formula (3) can be obtained, which is based on assuming the same developing law of concrete elastic module and tensile strength:

$$
K(\tau)=f\left(\frac{\partial T}{\partial l}\right) g(\tau)
$$

Comparing the calculated safety factor $K$ with (3) and with finite element method in Figure 9, it can be seen that they have a good agreement in most areas. To show the curves of the 6 cases more clearly, they are separately shown in two plots in Figure 9. 
TABLE 8: Calculation condition of case series 5.

\begin{tabular}{lcccc}
\hline Case & $\begin{array}{c}\text { Air temperature } T_{a} \\
\left({ }^{\circ} \mathrm{C}\right)\end{array}$ & $\begin{array}{c}\text { Pipe inlet water } \\
\text { temperature } T_{w}\left({ }^{\circ} \mathrm{C}\right)\end{array}$ & Surface insulation & Note \\
\hline $5-1$ & $25.0 \pm 5.0$ & & & The other condition is same as case \\
$5-2$ & $20.0 \pm 5.0$ & 15.0 & $2.0 \mathrm{~cm}$ EPE material on all free face & series 1 \\
$5-3$ & $15.0 \pm 5.0$ & & & \\
$5-4$ & $10.0 \pm 5.0$ & & & \\
\hline
\end{tabular}

TABLE 9: Main materials' parameters of different concrete materials.

\begin{tabular}{|c|c|c|c|c|c|c|c|c|c|}
\hline \multirow[t]{2}{*}{ Material number } & \multicolumn{3}{|c|}{$\begin{array}{c}\text { Adiabatic temperature }\left({ }^{\circ} \mathrm{C}\right) \\
\theta(\tau)=T_{0} \times\left(1-e^{-a \tau^{b}}\right)\end{array}$} & \multicolumn{3}{|c|}{$\begin{array}{l}\text { Elastic module }(\mathrm{GPa}) \\
E(\tau)=E_{0} \times\left(1-e^{-a_{1} \tau^{b_{1}}}\right)\end{array}$} & \multicolumn{3}{|c|}{$\begin{array}{l}\text { Tensile strength (MPa) } \\
f_{t}(\tau)=f_{0} \times\left(1-e^{-a_{2} \tau^{b_{2}}}\right)\end{array}$} \\
\hline & $\theta_{0}$ & $a$ & $b$ & $E_{0}$ & $a_{1}$ & $b_{1}$ & $f_{0}$ & $a_{2}$ & $b_{2}$ \\
\hline 1 & 23.0 & 0.202 & 0.900 & 33.72 & 0.652 & 0.219 & 2.96 & 0.078 & 0.749 \\
\hline 2 & 28.0 & 0.209 & 0.936 & 47.64 & 0.545 & 0.270 & 4.20 & 0.100 & 0.700 \\
\hline 3 & 27.5 & 0.385 & 0.613 & 44.64 & 0.287 & 0.408 & 2.73 & 0.252 & 0.500 \\
\hline 4 & 17.5 & 0.198 & 0.804 & 38.88 & 0.431 & 0.307 & 2.39 & 0.040 & 0.880 \\
\hline 5 & 21.4 & 0.302 & 0.689 & 43.80 & 0.428 & 0.315 & 2.57 & 0.060 & 0.825 \\
\hline 6 & 22.9 & 0.221 & 0.665 & 47.04 & 0.269 & 0.436 & 2.76 & 0.087 & 0.737 \\
\hline 7 & 20.4 & 0.282 & 0.621 & 45.96 & 0.245 & 0.450 & 2.62 & 0.064 & 0.805 \\
\hline
\end{tabular}

TABLE 10: The calculation condition of case series 6 .

\begin{tabular}{cccc}
\hline $\begin{array}{c}\text { Air } \\
\text { Case }\end{array}$ & $\begin{array}{c}\text { Initial } \\
\text { temperature } \\
T_{a}\left({ }^{\circ} \mathrm{C}\right)\end{array}$ & $\begin{array}{c}\text { temperature } T_{0} \\
\left({ }^{\circ} \mathrm{C}\right)\end{array}$ & Note \\
\hline $6-1$ & & 25.0 & No pipe cooling and no \\
$6-2$ & 20.0 & 20.0 & surface insulation measure \\
$6-3$ & & 15.0 & \\
\hline
\end{tabular}

\section{The Feasibility of the Basic Formula under Different Boundary Conditions}

3.1. Considering Daily Variation of Air Temperature. In the practical site situation, the air temperature always keeps changing every day and night. A daily variation of air temperature of about $10^{\circ} \mathrm{C}$ is considered in case series 2 which is based on case series 1 . The detailed conditions can be seen in Table 5.

Figure 10 shows the influence of daily variation of air temperature on the surface layer concrete. It can be seen that although the temperature of the point in $0.5 \mathrm{~m}$ deep has nearly no daily wave, the temperature of the point in $0.05 \mathrm{~m}$ deep keeps changing with the air temperature. Consequently, the temperature spatial gradient defined in the basic model will be influenced by the daily variation of air temperature. The surface safety factor will be influenced accordingly.

Figure 11 shows the relation between concrete surface safety factor and temperature spatial gradient in case series 2. In this case series, the time step is $0.25 \mathrm{~d}$. When the calculation result in one case is observed separately by $0.0 \mathrm{~d}$, $0.25 \mathrm{~d}, 0.50 \mathrm{~d}$, and $0.75 \mathrm{~d}$ in every day, it can be found in Figure 12 that the maximum temperature spatial gradient

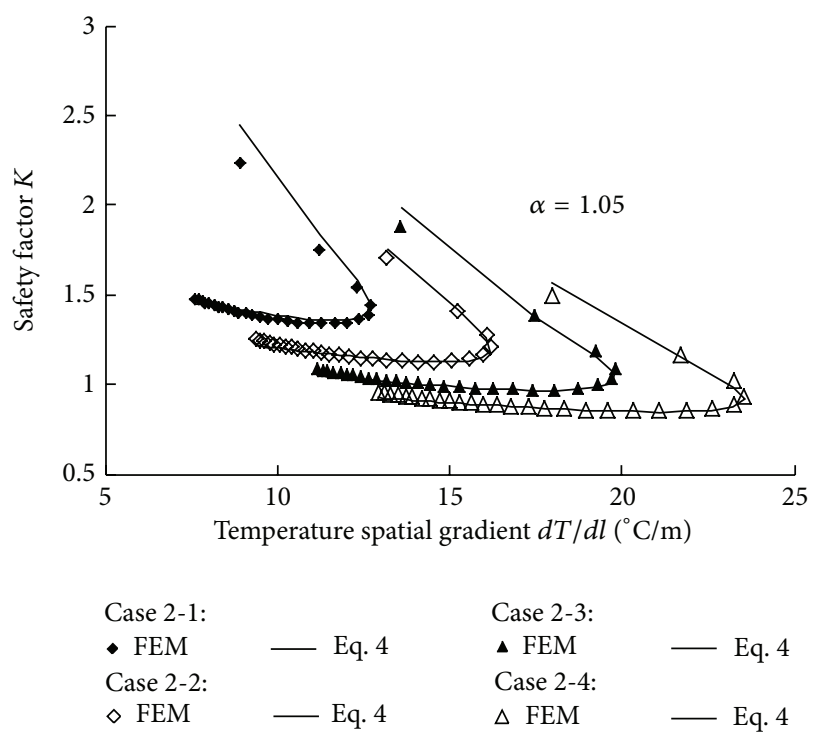

FIGURE 15: Comparison between calculated values by FEM and (4).

or the minimum safety factor always appears at the time of 0.25 d every day, which means this time is the most dangerous moment. For this reason, if the concrete at this time does not crack, then at other times the concrete will be safe enough. So the calculation result of $0.25 \mathrm{~d}$ in every day from every case of series 2 is extracted to be studied further in Figure 13.

The minimum safety factor of case series 2 calculated by FEM and (3) is compared in Figure 14. It can be seen that they meet well in most areas. In order to increase the precision 
TABLE 11: The relation between model parameter value and concrete material.

\begin{tabular}{lccccccc}
\hline Material number & 1 & 2 & 3 & 4 & 5 & 6 & 7 \\
\hline Parameter $\alpha$ & 0.8 & 0.85 & 0.85 & 0.75 & 0.7 & 0.95 & 1.1 \\
\hline Parameter $\gamma$ & 0.9 & 0.9 & 1.0 & 1.0 & 1.0 & 1.0 & 1.2 \\
\hline
\end{tabular}

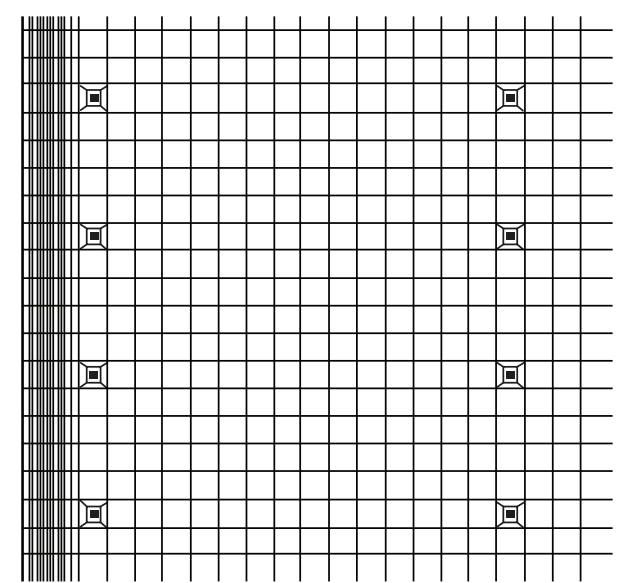

(a)

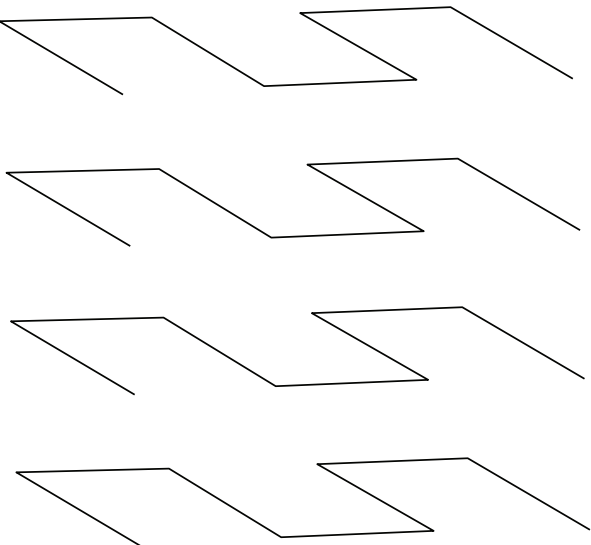

(b)

FIGURE 16: The layout of cooling pipe in the test model. (a) Local mesh section with pipe inlets and outlets. (b) Three-dimensional pipeline layout.

further, a parameter $\alpha$ is introduced into the model. The new formula is expressed by

$$
K(\tau)=\alpha f\left(\frac{\partial T}{\partial l}\right) g(\tau) .
$$

Figure 15 shows that when $\alpha$ equals 1.05 , the calculated values by FEM and (4) meet better. In fact, the value by (3) is a little less than FEM which will cause a little more safety measure in engineering. Therefore, it will be safer to set the value of $\alpha$ between 1.0 and 1.05 .

3.2. Considering Pipe Cooling. Cooling pipe is used widely in the construction of mass concrete $[17,18]$; will it influence obviously the calculation result of the proposed model? It is necessary to research this feasibility further.

The unsteady temperature field including cooling pipe is always a hard problem. An explicit cooling pipe iterative algorithm [19] is applied in the simulation of this paper.

Insert four pipes into the finite element test model. The inlet and outlet of pipes can be seen in the local mesh on the left of Figure 16 and the three-dimensional pipelines on the right. The distance between concrete surface and pipe is $1.0 \mathrm{~m}$. Both of the horizontal and vertical distances of pipelines are $2.0 \mathrm{~m}$. The pipe is adopted as one of the most common types in concrete engineering with an inner diameter of $0.028 \mathrm{~m}$ and the material of high-density polyethylene.

Based on case series 1, pipe cooling measure is added in case series 3 with the inlet water temperature of $15.0^{\circ} \mathrm{C}$. In order to analyze the influence of pipe cooling separately, the daily variation of air temperature will not be considered in case series 3. The detailed condition is shown in Table 6 .

Figure 17 shows the comparison between the calculation results of case series 3 by FEM and (3). Figure 18 shows the comparison between the calculation results of case series 3 by FEM and (4) in which $\alpha$ equals 1.10.

\subsection{Considering Both Daily Variation of Air Temperature and} Pipe Cooling. In order to meet the requirement of practical situation, daily variation of air temperature and pipe cooling should be considered in the test block at the same time. In case series 4, pipe cooling measure is added on the basis of case series 2 calculation condition. The detailed condition can be seen in Table 7 .

Figure 19 shows the relation between the temperature spatial gradient and the surface safety factor at different ages in case series 4 . To observe it clearly, the results of the four times in every day of case 4-1 are drawn separately in Figure 20. It can be found that the temperature spatial gradient of $0.25 \mathrm{~d}$ is maximum and the safety factor of the time is minimum. Therefore, the results of $0.25 \mathrm{~d}$ in every case are drawn in Figure 21; the calculated value of (3) is shown as well. From this figure, the results by FEM and (3) do not meet very well, especially in the later age. While in Figure 22, the results become better when (4) is applied and $\alpha$ equals 1.10 .

3.4. Considering Both Daily Variation of Air Temperature, Pipe Cooling, and Surface Insulation. In winter or cold wave time, surface insulation measure is always taken to protect the concrete in early age. In case series 5 , a layer of $2.0 \mathrm{~cm}$ thick expandable polyethylene (EPE), which is one of the most common application concrete insulation materials in construction, is added on the basis of case series 4 calculation condition. The detailed calculation condition is shown in Table 8 .

Figure 23 shows the relation between the temperature spatial gradient and the surface safety factor at different 


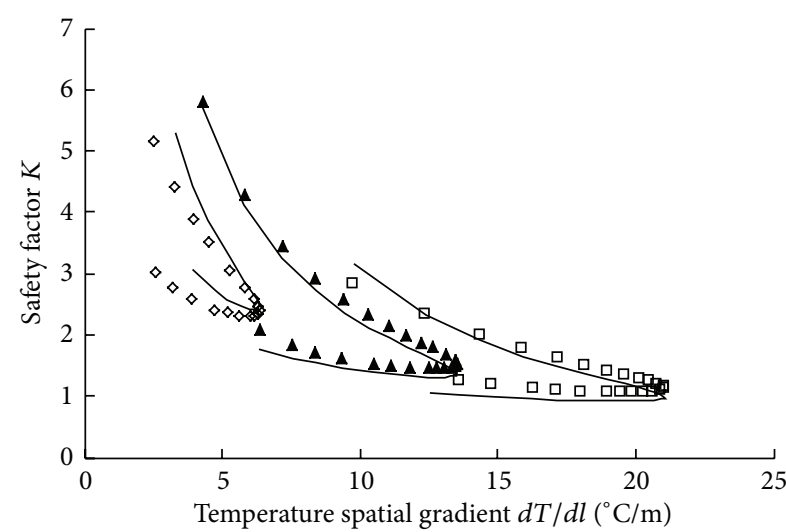

Case 3-1: $\diamond$ FEM

Case 3-5:

$\triangle \mathrm{FEM}$

Case 3-3:

$\square$ FEM
Eq. 3

- Eq. 3

- Eq. 3

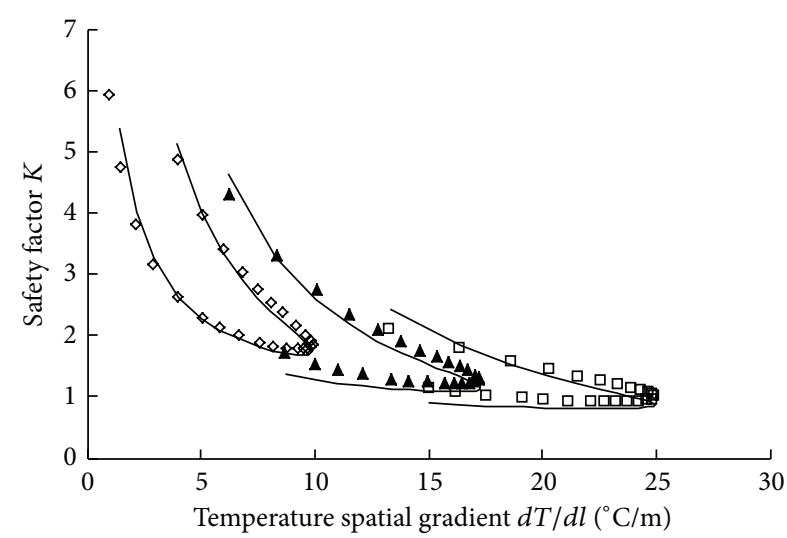

Case 3-2:

$\diamond$ FEM

Case 3-4:

$\triangle \mathrm{FEM}$

Case 3-6:

$\square$ FEM

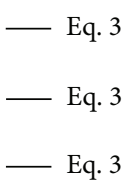

(b)

(a)

FIGURE 17: Comparison of case series 3 results between FEM and (3).
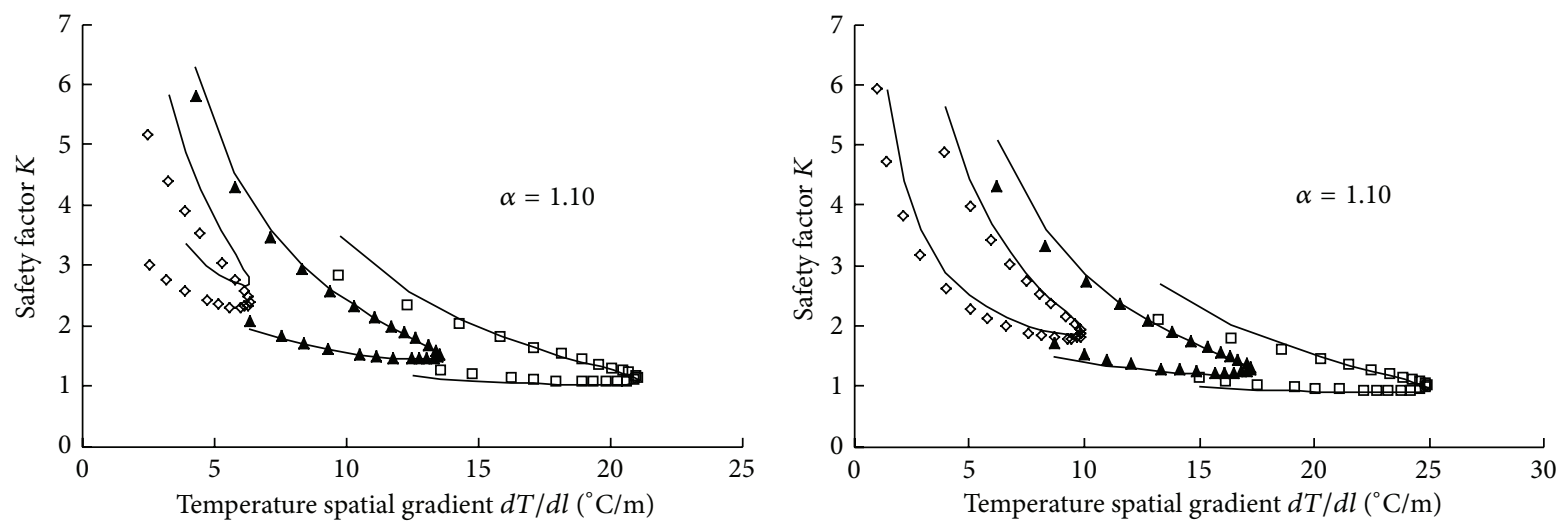

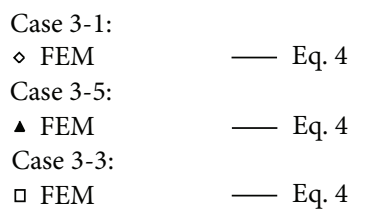

(a)

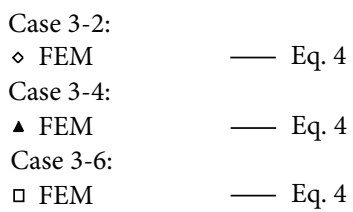

(b)

FIGURE 18: Comparison of case series 3 results between FEM and (4).

ages in case series 5. To observe it clearly, the results of the four times in every day of case 5-1 are drawn separately in Figure 24. Being similar to case 4-1, the most dangerous situation appears at $0.25 \mathrm{~d}$ of every day. Therefore, the results of $0.25 \mathrm{~d}$ in every case are drawn in Figure 25; the calculated value of (3) is shown as well. From the figure, the results by FEM and (3) have obvious difference. When (4) is applied and $\alpha$ equals 1.15 , the results become much closer, as shown in Figure 26.

\section{The Applicability of the Model for Different Concrete Materials}

4.1. The Limitation of Basic Model and Calibration. The developing laws of concrete elastic module and tensile strength are assumed same as in Section 3. In most concrete engineering, their developing laws are different, which will influence the concrete surface safety factor obviously. In this section, (4) is calibrated further to adapt the authentic different concrete. 


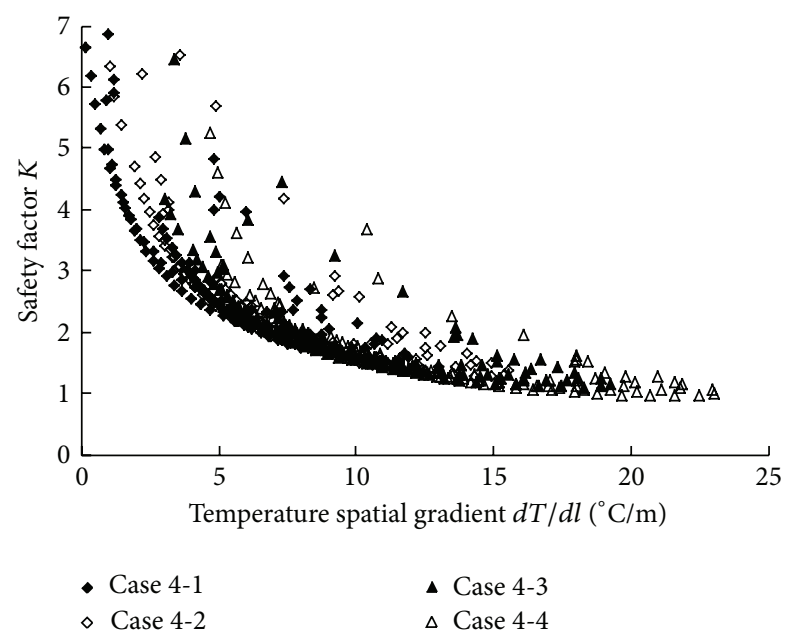

FIGURE 19: Relation between concrete surface safety factor and temperature spatial gradient in case series 4 .
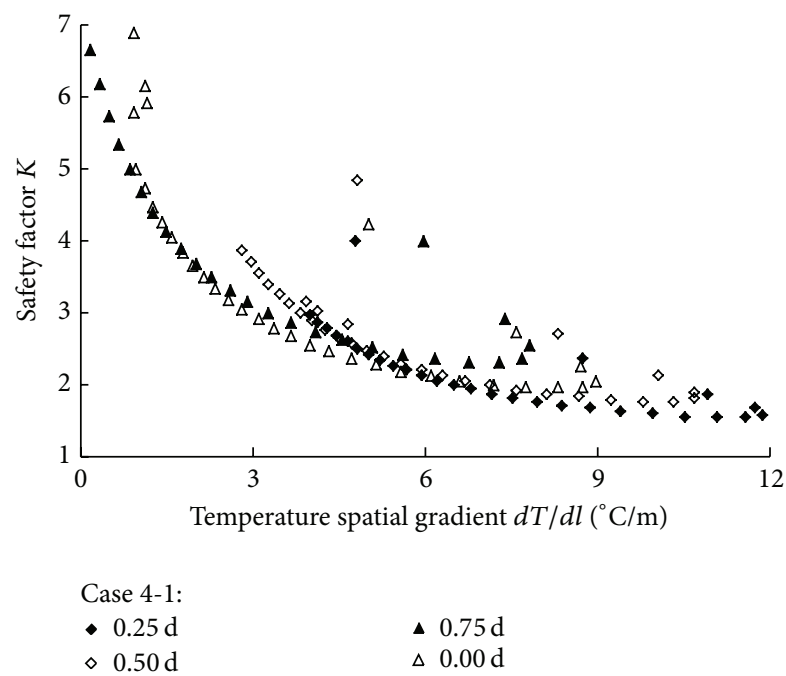

FIGURE 20: Relation between concrete surface safety factor and temperature spatial gradient at different times of every day in case 4-1.

A calibration factor $\eta^{\gamma}$ is introduced into (4) to consider the influence of tensile strength and elastic module.

$\eta$ is the ratio of axial tensile strength and elastic module developing law, as shown in

$$
\eta=\frac{\left(1-e^{-a_{1} \tau^{b_{1}}}\right)}{\left(1-e^{-a_{2} \tau^{b_{2}}}\right)},
$$

in which $\left(1-e^{-a_{1} \tau^{b_{1}}}\right)$ is the developing law of axial tensile strength, and $\left(1-e^{-a_{2} \tau^{b_{2}}}\right)$ is the developing law of elastic module. $a_{1}, b_{1}, a_{2}, b_{2}$ are the parameters of the composite index formula. As for different age strength, the rebound number method [20] can be easily applied to obtain the values which will decide the parameters. For some prediction cases, concrete creep effect must be included. As in the
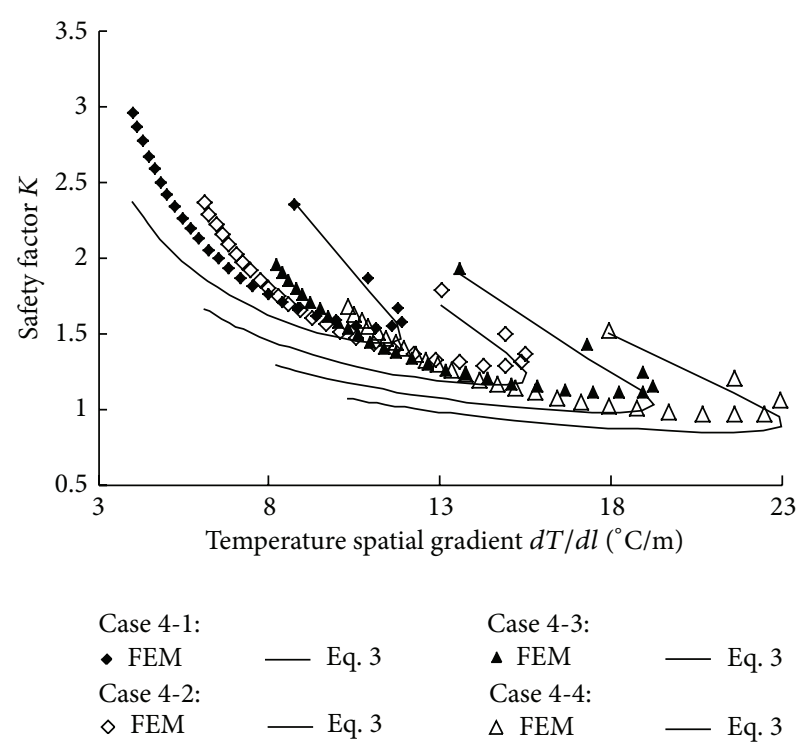

Figure 21: Comparison of case series 4 results at $0.25 \mathrm{~d}$ every day between FEM and (3).
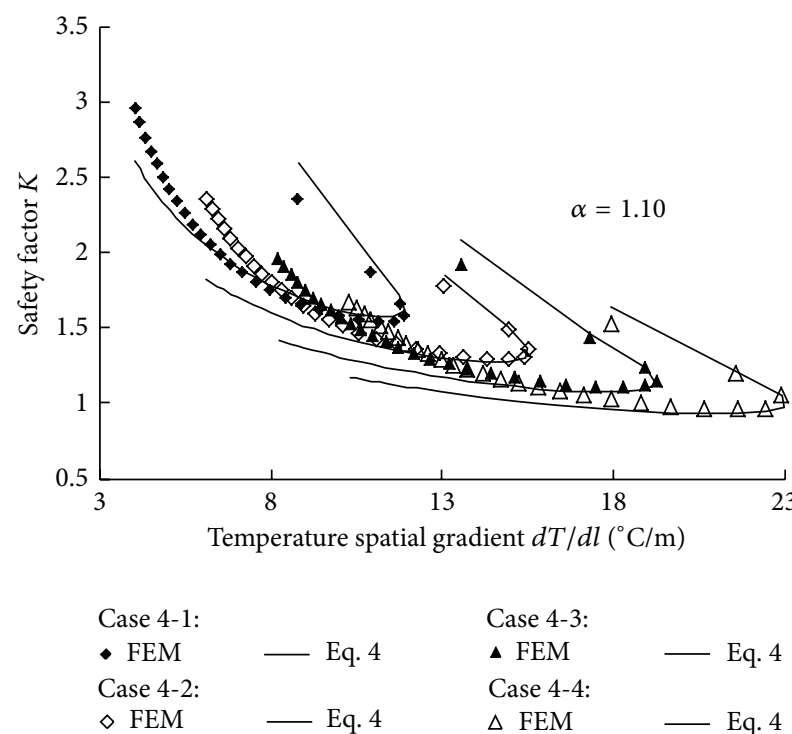

FIgURE 22: Comparison of case series 4 results at $0.25 \mathrm{~d}$ every day between FEM and (4).

finite element method simulation, the creep effect can always be considered in the expression of elastic module with an equivalent formula whose form is same but parameters' values are different. In calculation, the essential function of the creep effect is to lower the elastic module to a certain extent.

$\gamma$ is a constant for a certain concrete material. Its value usually is between 0.9 and 1.2 , which will vary with concrete material. The detailed information will be shown in later content of this paper. 


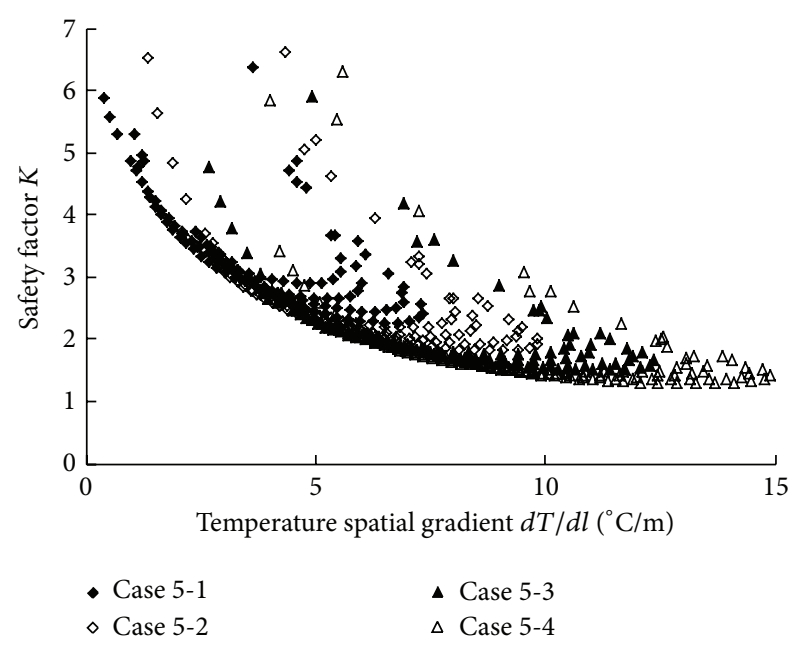

FIGURE 23: Relation between concrete surface safety factor and temperature spatial gradient in case series 5 .

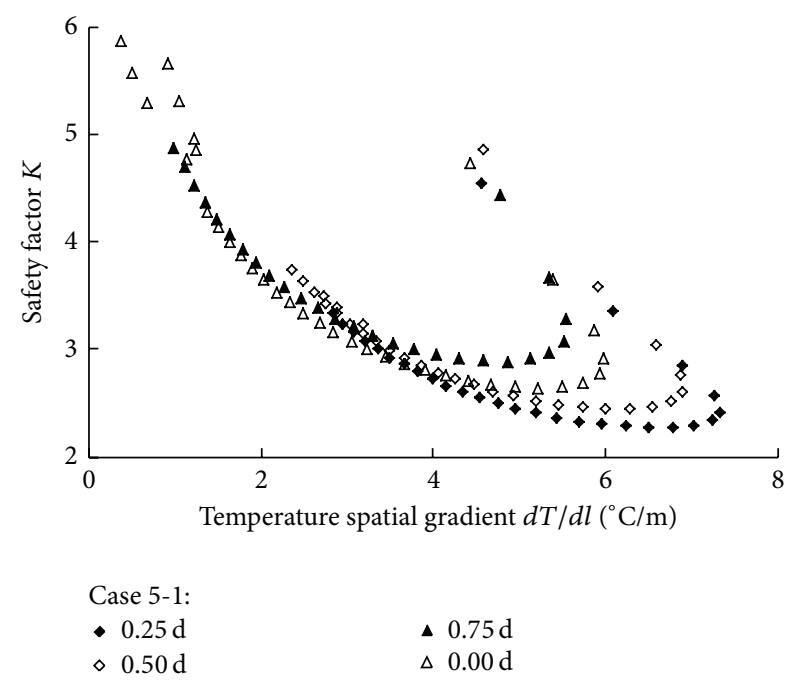

FIGURE 24: Relation between concrete surface safety factor and temperature spatial gradient at different times of every day in case 5-1.

After the above modification, the proposed model can be expressed by

$$
K(\tau)=\alpha f\left(\frac{\partial T}{\partial l}\right) \eta^{\gamma} g(\tau),
$$

in which $f(\partial T / \partial l), g(\tau)$, and $\eta$ can be obtained separately by (1), (2), and (5). The definition of the parameters is same as the above equations, which will not be repeated again.

4.2. Verification of the Calibrated Model. Based on two mass concrete engineering in West China [21, 22], 7 types of concrete material are selected to verify the applicability of (6). Table 9 shows the detailed parameters' values of different concrete materials, in which materials 1 3 are the normal concrete; materials $4 \sim 7$ are the rolled compacted concrete (RCC). Case series 6 is planned in Table 10.
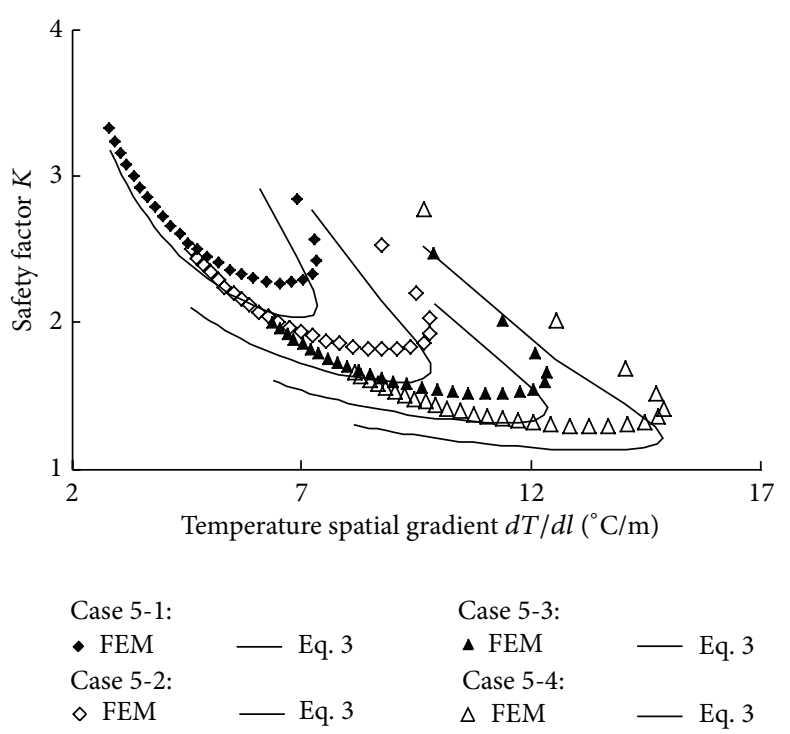

Figure 25: Comparison of case series 4 results at $0.25 \mathrm{~d}$ every day between FEM and (3).
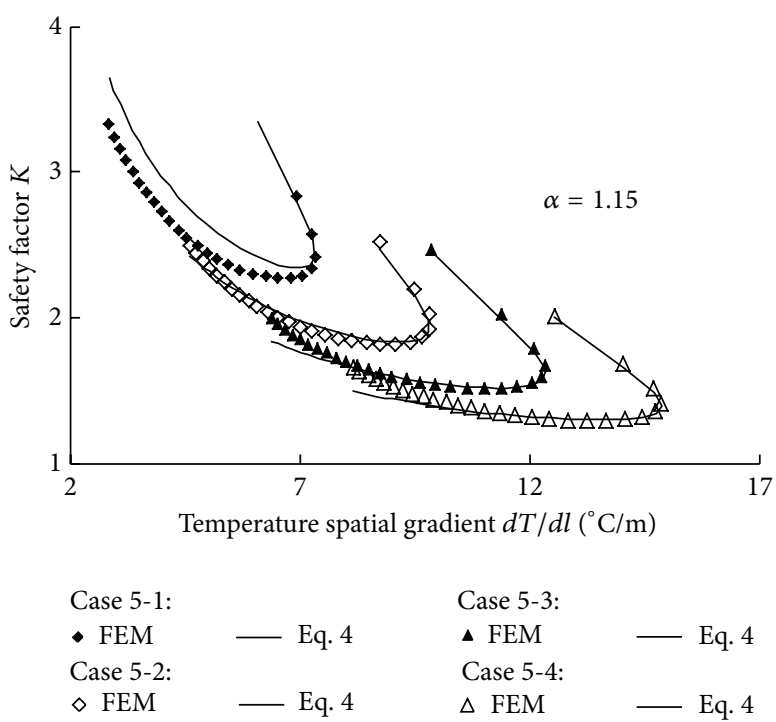

FIgURE 26: Comparison of case series 5 results at $0.25 \mathrm{~d}$ every day between FEM and (4).

4.3. Test Results and Analysis. The 7 kinds of material in Table 9 are separately applied in the 3 different calculation conditions in Table 10. Therefore there are indeed 21 calculation cases in total. Figures 27, 28, 29, 30, 31, 32, and 33 are the comparison of calculation result by FEM and (6) with different materials and different calculation conditions.

According to the comparison, it is found that the calculation result by FEM and (6) meet well, especially in early age.

Table 11 lists the values of parameter $\alpha$ and $\gamma$ in different conditions. It can be seen that the value of $\alpha$ ranges from 0.7 to 1.1 and the value $\gamma$ ranges from 0.9 to 1.2. For normal concrete materials 1 3, the parameter value varies little, while for the RCC materials $4 \sim 7$, the parameter value changes more. 


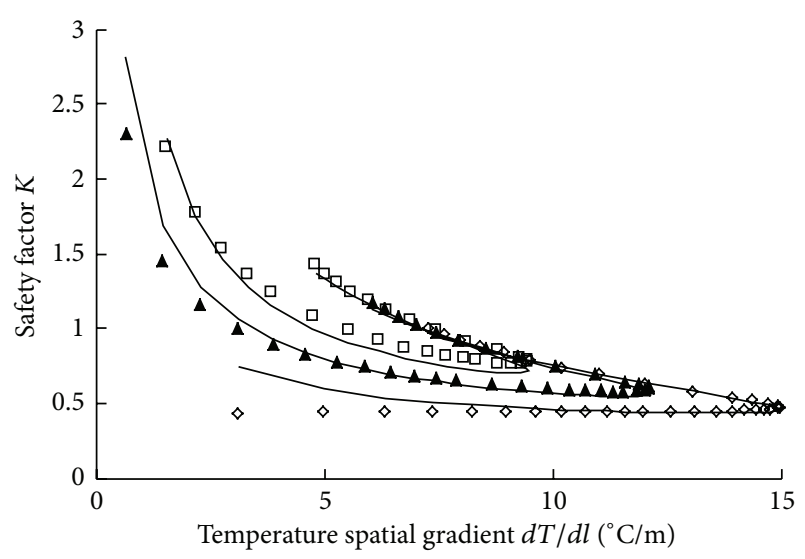

Case 6-1:
ऽFEM
Case 6-2:
$\begin{aligned} & \text { A FEM } \\ & \text { Case 6-3: }\end{aligned}$
$\square$ FEM 6 Eq. 6

Figure 27: Comparison of case series 6 results using material 1 between FEM and (6).

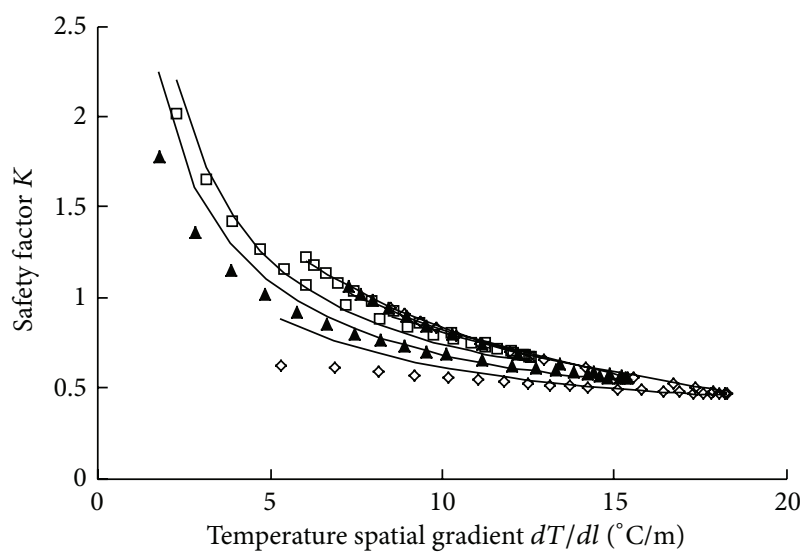

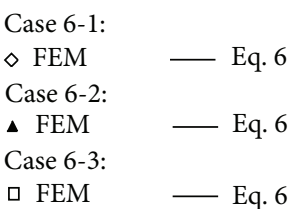

Figure 28: Comparison of case series 6 results using material 2 between FEM and (6).

In the engineering application, the two parameters can be decided from Table 11 by comparing the concrete material properties with the value in Table 9. And the concrete temperature spatial gradient $\partial T / \partial l$ can be obtained by two sensors in $0.05 \mathrm{~m}$ deep and $0.50 \mathrm{~m}$ deep. Then the surface safety factor to prevent crack at any age can be calculated by (6) easily. The precision of the equation calculation result is high as FEM, especially in early age when the surface cracking appears most often. During the dynamic observation and calculation in construction, if the safety factor tends to be

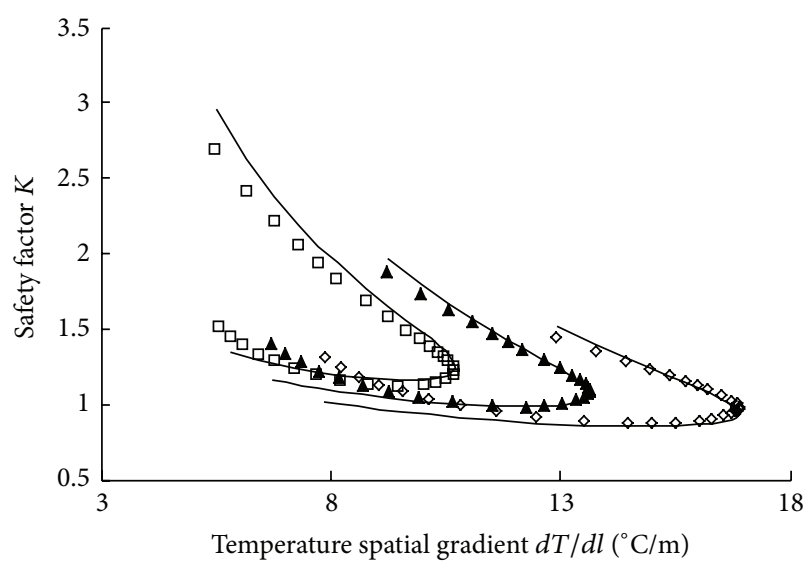

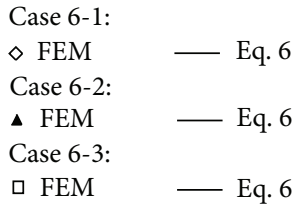

Figure 29: Comparison of case series 6 results using material 3 between FEM and (6).

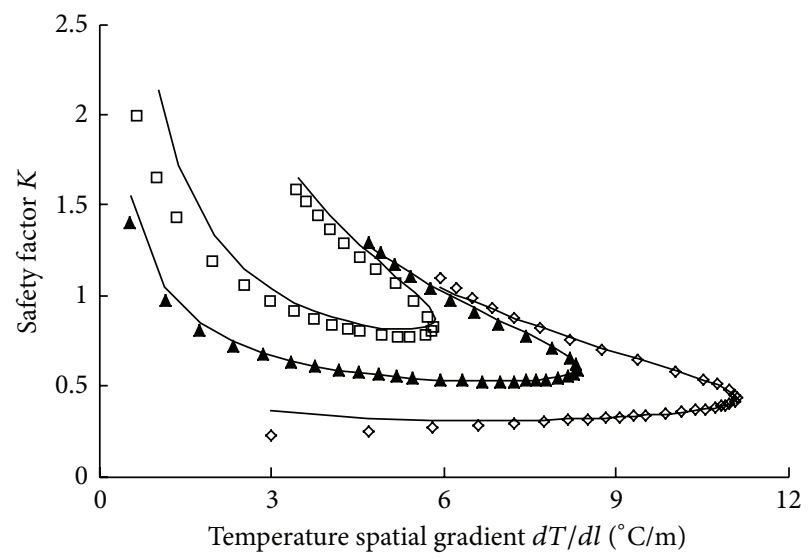

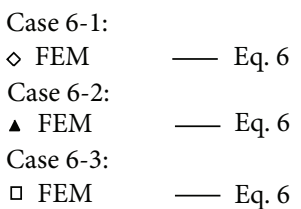

FIgURE 30: Comparison of case series 6 results using material 4 between FEM and (6).

lower than the expected value, necessary temperature control method should be taken to reduce the temperature difference between concrete inside and outside, such as thickening cover insulation material or enhancing the pipe cooling.

\section{Conclusion}

The reasonable definition and criteria of the temperature difference between concrete inside and outside are researched in this paper in order to prevent the surface cracking in 


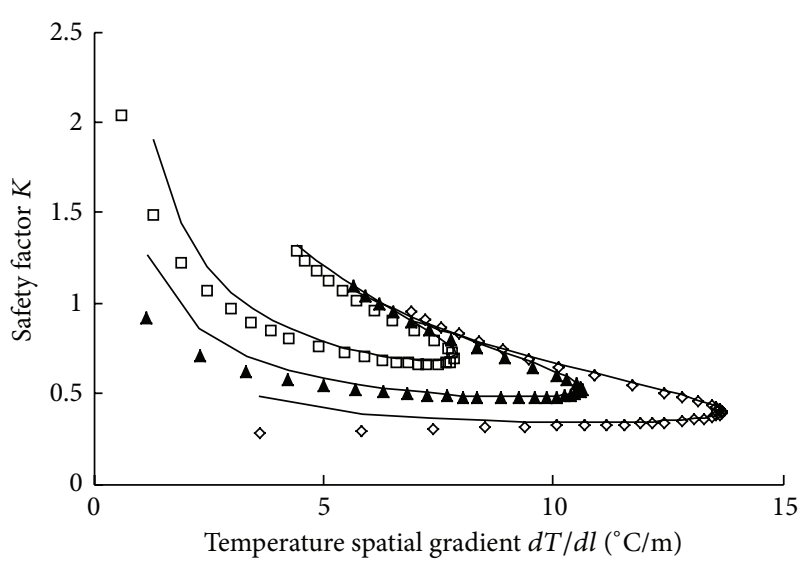

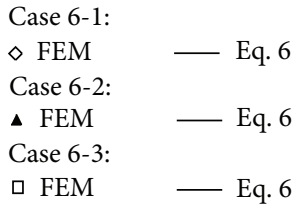

FIGURE 31: Comparison of case series 6 results using material 5 between FEM and (6).

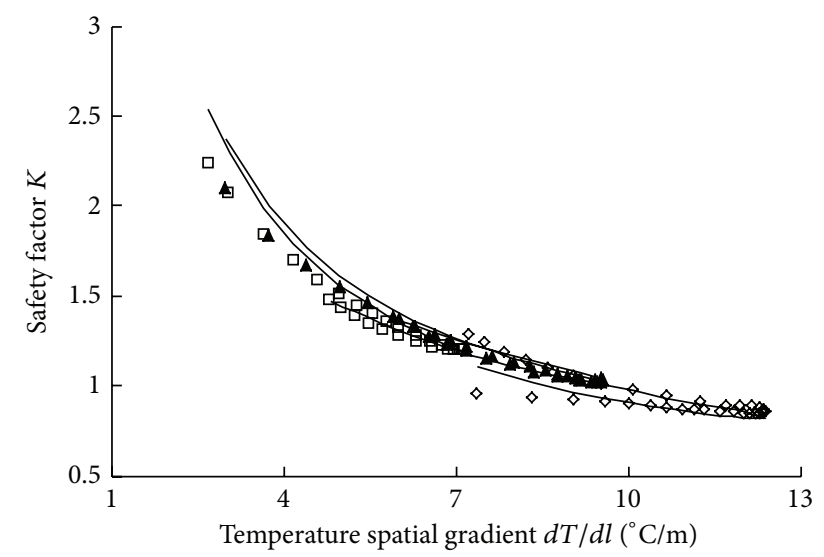

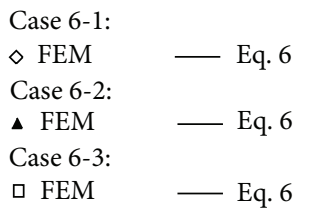

Figure 32: Comparison of case series 6 results using material 6 between FEM and (6).

early age. The surface concrete temperature spatial gradient in $0.5 \mathrm{~m}$ deep is found as a more reasonable and feasible index. Then a new model, which can be used to calculate the surface safety factor simply, is deduced. If the necessary parameters are known, the surface safety factor of a certain age can be obtained according to the concrete temperature spatial gradient of the age. During concrete construction the concrete temperature spatial gradient can be recorded easily by two or more temperature sensors. With the help

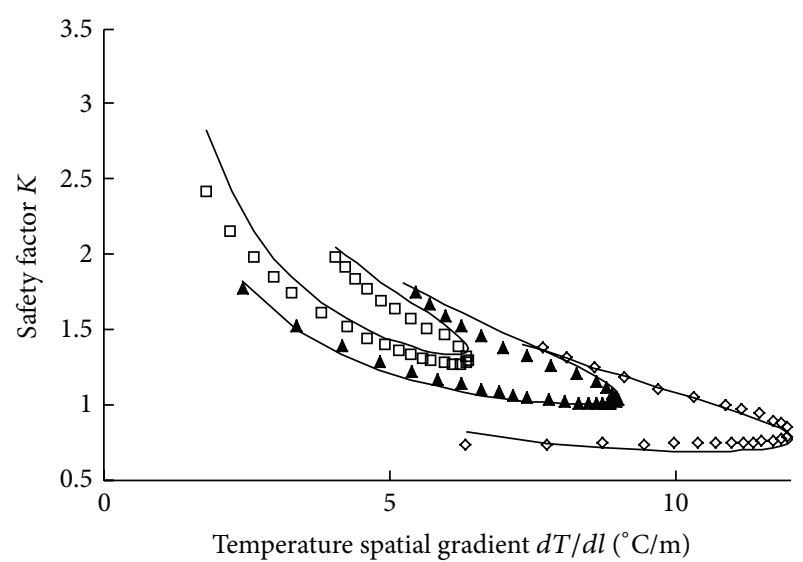

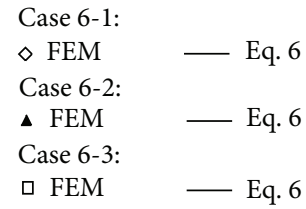

FIgURE 33: Comparison of case series 6 results using material 7 between FEM and (6).

of the proposed model, the surface safety factor can be adjusted by observing and controlling the temperature spatial gradient dynamically. The precision of the model under different conditions is tested and improved by comparison with FEM. The last proposed model (6) can meet the practical engineering requirement, which will bring convenience to designer and constructor. In the future, it will be further verified in more engineering applications.

\section{Conflict of Interests}

The authors declare that there is no conflict of interests regarding the publication of this paper.

\section{Acknowledgments}

This work is supported by the National Natural Science Foundation of China (51109071) and Huaian Hydraulic Academician Work Station.

\section{References}

[1] H. S. Shang and T. H. Yi, "Behavior of HPC with fly ash after elevated temperature," Advances in Materials Science and Engineering, vol. 2013, Article ID 478421, 7 pages, 2013.

[2] H. S. Shang and T. H. Yi, "Freeze-thaw durability of airentrained concrete," The Scientific World Journal, vol. 2013, Article ID 650791, 6 pages, 2013.

[3] A.C.I. 231, "Report on early-age cracking: causes, measurement and mitigation," Tech. Rep. ACI 231R-10, American Concrete Institute, Farmington Hills, Mich, USA, 2010.

[4] B. Klemczak and K. W. Agnieszka, "Early age thermal and shrinkage cracks in concrete structures-description of the 
problem," Architecture Civil Engineering Environment, no. 2, pp. 35-48, 2011.

[5] W. J. Weiss, D. P. Bentz, A. Schlinder, and P. Lura, "Internal curing-constructing more robust concrete," Structure Magazine, no. 1, pp. 10-14, 2012.

[6] D. P. Bentz and W. J. Weiss, "React: reducing early age cracking today," Concrete Plant International, no. 3, pp. 56-62, 2008.

[7] Bureau of Reclamation, Concrete Manual, U.S. Department of the Interior, 8th edition, 1988.

[8] P. B. Bamforth, Early-Age Thermal Crack Control in Concrete (C660), CIRIA, London, UK, 2007.

[9] B. F. Zhu, Thermal Stresses and Temperature Control of Mass Concrete, China Electric Power Press, Beijing, China, 2nd edition, 1999.

[10] J. K. Kim, K. H. Kim, and J. K. Yang, "Thermal analysis of hydration heat in concrete structures with pipe-cooling system," Computers and Structures, vol. 79, no. 2, pp. 163-171, 2001.

[11] T. G. Myers, N. D. Fowkes, and Y. Ballim, "Modeling the cooling of concrete by piped water," Journal of Engineering Mechanics, vol. 135, no. 12, pp. 1375-1383, 2009.

[12] Y. Cui and H. Dong, "The Influence of surface dissipation condition on the inside temperature gradient of concrete structure," 21st Century Building Materials, vol. 2, no. 6, pp. 2628, 2010.

[13] H. Guan, Q. Zhang, and Z. Luo, “Total-thickness laboratory rut tests for asphalt surface course under temperature gradient," China Civil Engineering Journal, vol. 44, no. 6, pp. 143-147, 2011.

[14] B. Choubane and M. Tia, "Analysis and verification of thermalgradient effects on concrete pavement," Journal of Transportation Engineering, vol. 121, no. 1, pp. 75-81, 1995.

[15] C. N. Song, X. C. Wang, and J. B. Wei, "Numerical model of concrete pavement temperature gradient in desert area and emulation analysis," Journal of Dessert Research, vol. 27, no. 2, pp. 229-233, 2007.

[16] C. L. Townsend, Control of Cracking in Mass Concrete Structures, United States Department of the Interior, Bureau of Reclamation, 1981.

[17] J. He and A. Hoyano, "Experimental study of cooling effects of a passive evaporative cooling wall constructed of porous ceramics with high water soaking-up ability," Building and Environment, vol. 45, no. 2, pp. 461-472, 2010.

[18] S. Qiang, S.-K. Chen, L. Guo, and Z.-Q. Xie, "Numerical simulation of the construction for concrete crane beam on rock wall and the thermal parameters inversion," in Proceedings of the 2nd International Conference on Information Engineering and Computer Science (ICIECS '10), pp. 1-4, Wuhan, China, December 2010.

[19] Y. M. Zhu, Z. Q. Xu, and J. R. He, "A calculation method for solving temperature field of mass concrete with cooling pipes," Journal of Yangtze River Scientific Research Institute, vol. 20, no. 2, pp. 19-22, 2003.

[20] H. S. Shang, T. H. Yi, and L. S. Yang, "Experimental study on the compressive strength of big mobility concrete with nondestructive testing method," Advances in Materials Science and Engineering, vol. 2012, Article ID 345214, 6 pages, 2012.

[21] Y. M. Zhu, Research Report of the Concrete Temperature Control and Cracking Prevention During Construction for Caojie Dam Engineering, Hohai University, 2009.
[22] S. Qiang, Research Report of the Concrete Temperature Control and Cracking Prevention During Construction for Guandi RCC Dam Engineering, Hohai University, 2011. 


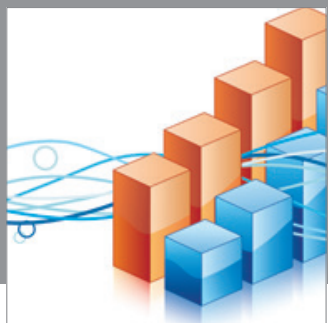

Advances in

Operations Research

mansans

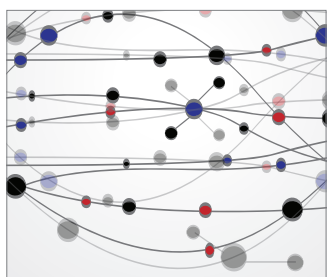

The Scientific World Journal
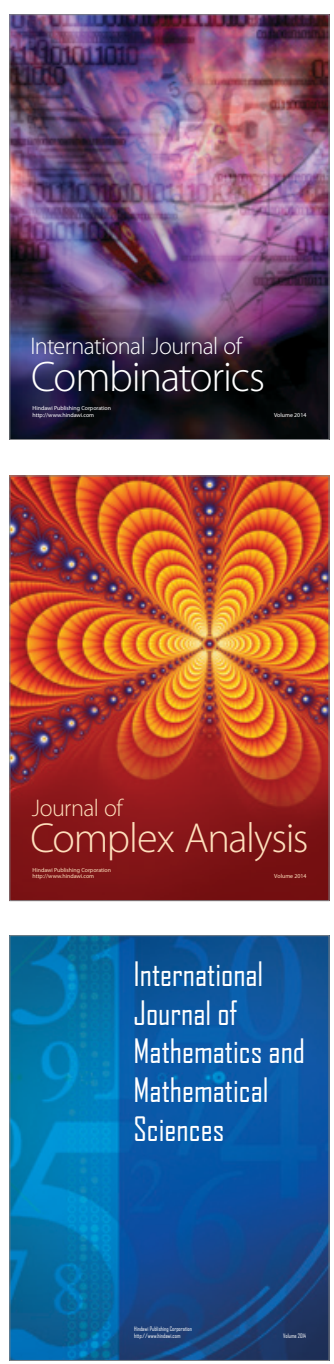
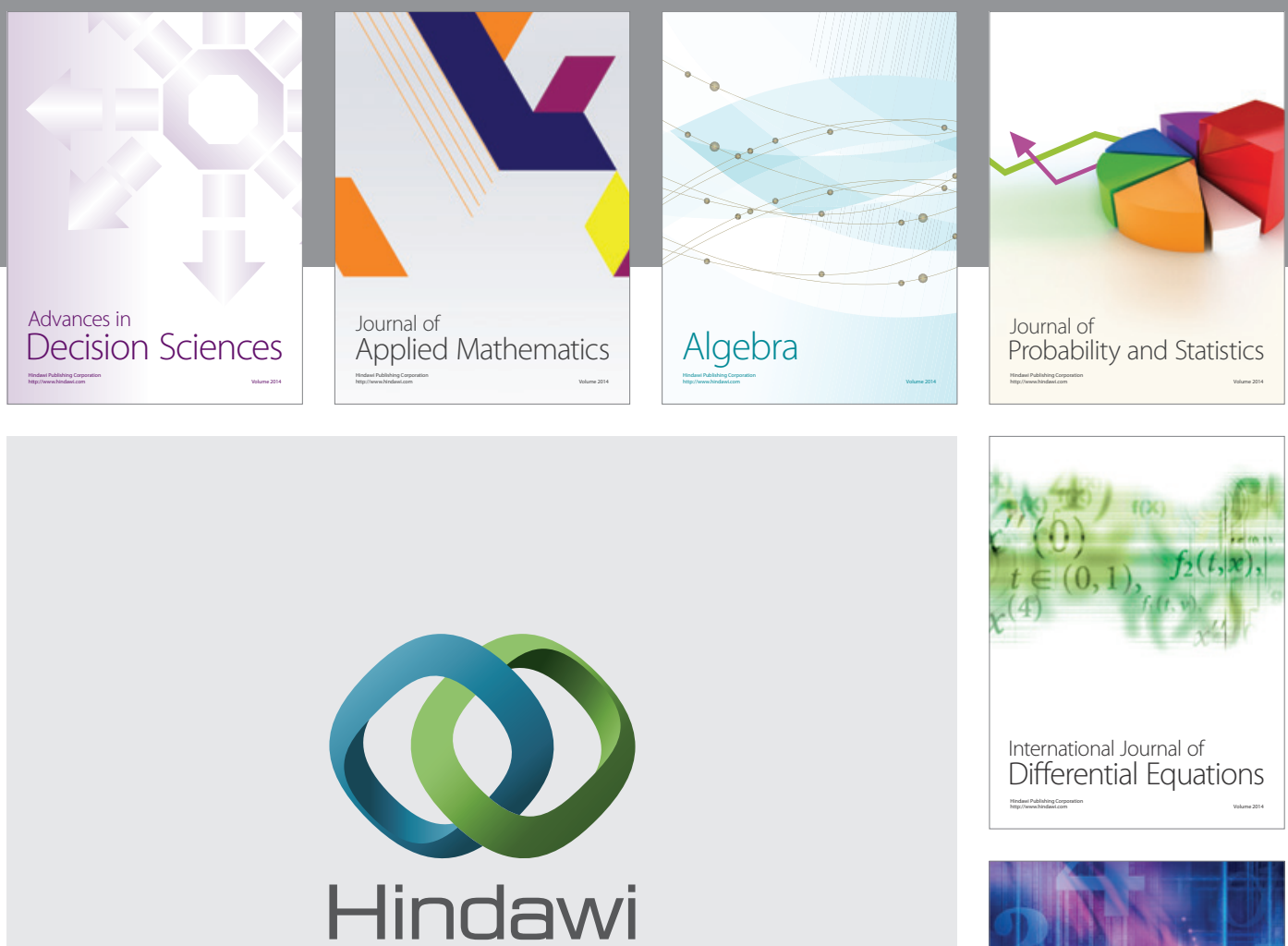

Submit your manuscripts at http://www.hindawi.com
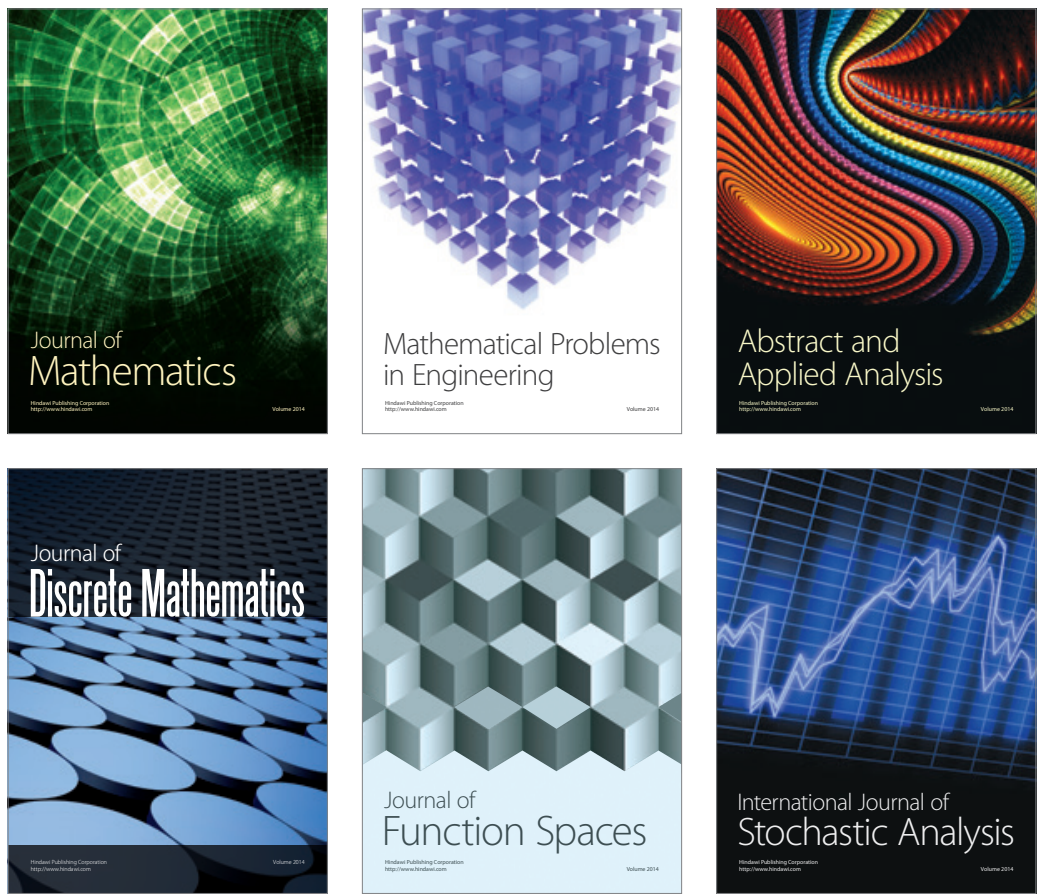

Journal of

Function Spaces

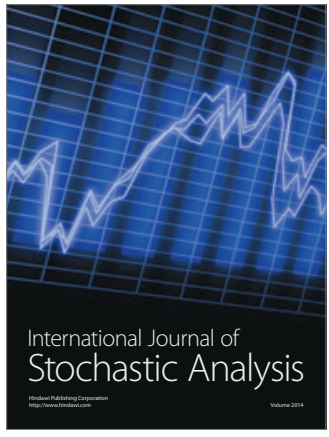

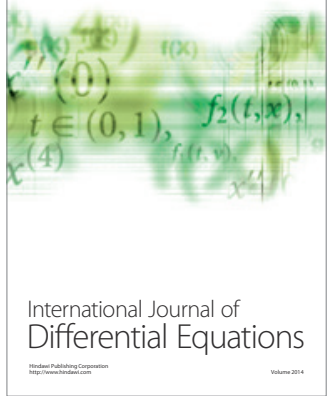
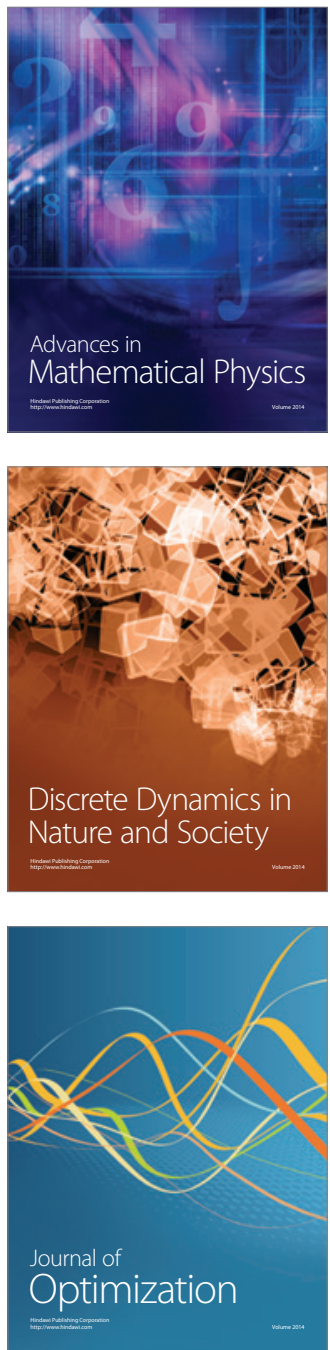